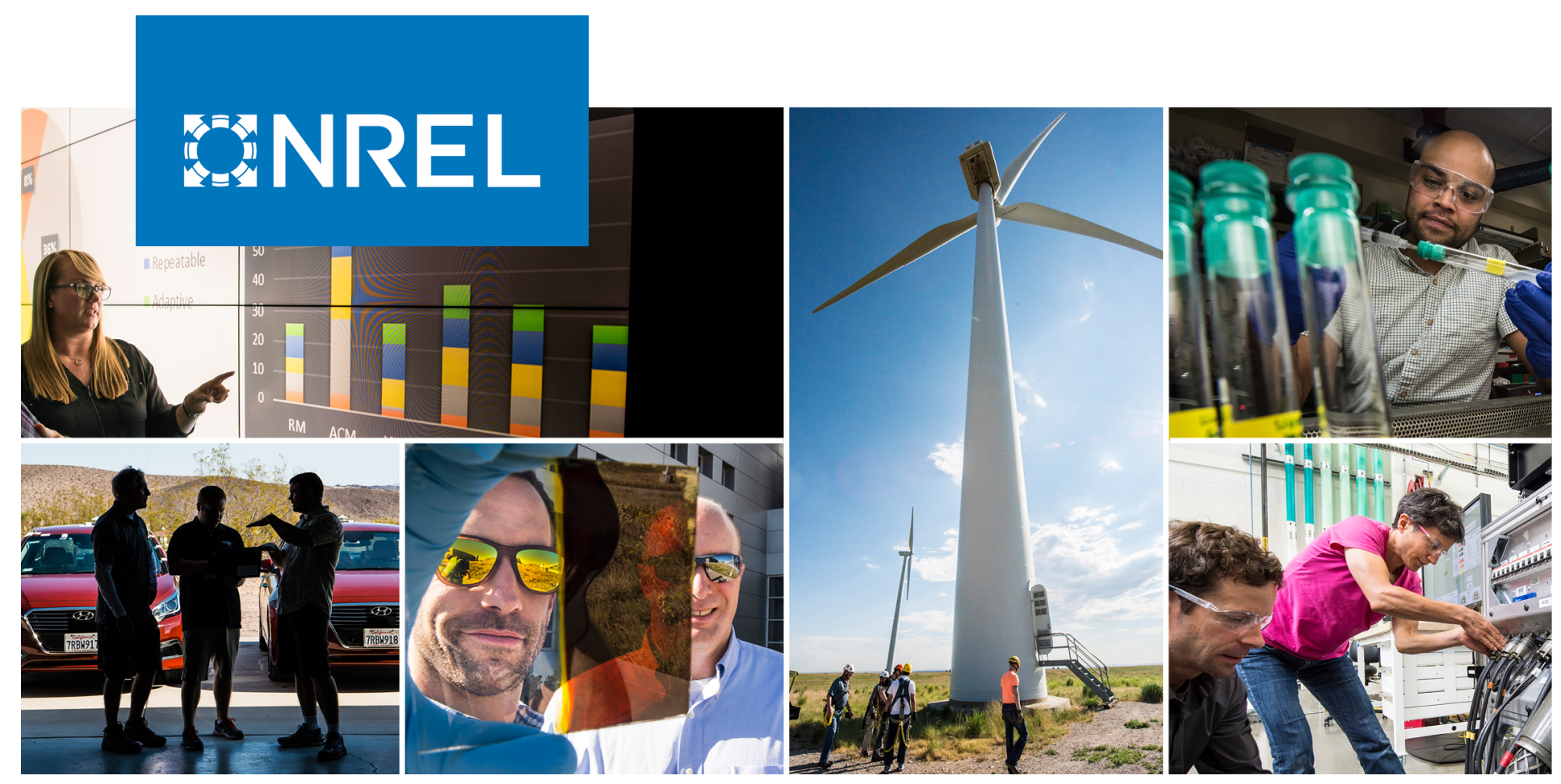

\title{
Distributed Wind Controls: A Research Roadmap for Microgrids, Infrastructure Resilience, and Advanced Controls Launchpad (MIRACL)
}

Jim Reilly, ${ }^{1}$ Ram Poudel, ${ }^{1}$ Venkat Krishnan, ${ }^{1}$ Robert Preus, ${ }^{1}$ lan Baring-Gould, ${ }^{1}$ Ben Anderson, ${ }^{1}$ Brian Naughton, ${ }^{2}$ Felipe Wilches-Bernal, ${ }^{2}$ and Rachid Darbali ${ }^{2}$

1 National Renewable Energy Laboratory 2 Sandia National Laboratories

NREL is a national laboratory of the U.S. Department of Energy Office of Energy Efficiency \& Renewable Energy Operated by the Alliance for Sustainable Energy, LLC

This report is available at no cost from the National Renewable Energy Laboratory (NREL) at www.nrel.gov/publications.
Technical Report NREL/TP-7A40-76748 January 2021 


\section{EAREL}

Distributed Wind Controls: A Research Roadmap for Microgrids, Infrastructure Resilience, and Advanced Controls Launchpad (MIRACL)

Jim Reilly, ${ }^{1}$ Ram Poudel, ${ }^{1}$ Venkat Krishnan, ${ }^{1}$ Robert Preus, ${ }^{1}$ Ian Baring-Gould, ${ }^{1}$ Ben Anderson, ${ }^{1}$ Brian Naughton, ${ }^{2}$ Felipe Wilches-Bernal, ${ }^{2}$ and Rachid Darbali ${ }^{2}$

1 National Renewable Energy Laboratory

2 Sandia National Laboratories

\section{Suggested Citation}

Reilly, Jim, Ram Poudel, Venkat Krishnan, Robert Preus, lan Baring-Gould, Ben Anderson,

Brian Naughton, Felipe Wilches-Bernal, and Rachid Darbali. 2021. Distributed Wind

Controls: A Research Roadmap for Microgrids, Infrastructure Resilience, and Advanced

Controls Launchpad (MIRACL). Golden, CO: National Renewable Energy Laboratory.

NREL/TP-7A40-76748. https://www.nrel.gov/docs/fy21osti/76748.pdf.

NREL is a national laboratory of the U.S. Department of Energy Office of Energy Efficiency \& Renewable Energy Operated by the Alliance for Sustainable Energy, LLC

This report is available at no cost from the National Renewable Energy Laboratory (NREL) at www.nrel.gov/publications.

Contract No. DE-AC36-08GO28308
Technical Report

NREL/TP-7A40-76748

January 2021

National Renewable Energy Laboratory 15013 Denver West Parkway Golden, CO 80401

303-275-3000 • www.nrel.gov 


\section{NOTICE}

This work was authored in part by the National Renewable Energy Laboratory, operated by Alliance for Sustainable Energy, LLC, for the U.S. Department of Energy (DOE) under Contract No. DE-AC36-08GO28308. Funding provided by U.S. Department of Energy Office of Energy Efficiency and Renewable Energy Wind Energy Technologies Office. The views expressed herein do not necessarily represent the views of the DOE or the U.S. Government.

This report is available at no cost from the National Renewable Energy Laboratory (NREL) at www.nrel.gov/publications.

U.S. Department of Energy (DOE) reports produced after 1991 and a growing number of pre-1991 documents are available free via www.OSTI.gov.

Cover Photos by Dennis Schroeder: (clockwise, left to right) NREL 51934, NREL 45897, NREL 42160, NREL 45891, NREL 48097, NREL 46526.

NREL prints on paper that contains recycled content. 


\section{Acknowledgments}

We are thankful to all project team members from partnering laboratories on the Microgrids, Infrastructure Resilience, and Advanced Controls Launchpad (MIRACL) project:

- Idaho National Laboratory

- Pacific Northwest National Laboratory.

We also express our sincere gratitude to our industry Advisory Board members for their valuable insights and real-world test system recommendations during the March 2020 Advisory Board meeting: Venkat Banunarayanan (National Rural Electric Cooperative Association), Chris Rose (Renewable Energy Alaska), Rob Wills (Intergrid), Paul Dockrill (Natural Resource Canada), Jeff Pack (POWER Engineers), Arvind Tiwari (GE Global Research), Kristin Swenson (Midcontinent Independent System Operator [MISO]), Jonathon Monken (PJM), and Scott Fouts (QED Wind Power).

In addition, we would like to thank Robert Wood, Dave Corbus, Brian Smith, and Paul Veers for their thoughtful review, and Michael Deneen and Sheri Anstedt for editorial support. 
List of Abbreviations and Acronyms

$\begin{array}{ll}\text { A } & \text { ampere } \\ \text { AC } & \text { alternating current } \\ \text { AEP } & \text { annual energy production } \\ \text { AGC } & \text { automatic generation control } \\ \text { ANSI } & \text { American National Standards Institute } \\ \text { APC } & \text { active power control } \\ \text { BESS } & \text { battery energy storage systems } \\ \text { DC } & \text { direct current } \\ \text { DER } & \text { distributed energy resource } \\ \text { DETL } & \text { Distributed Energy Technologies Laboratory (Sandia) } \\ \text { DFIG } & \text { doubly fed induction generator } \\ \text { DOE } & \text { U.S. Department of Energy } \\ \text { HECO } & \text { Hawaiian Electric Company, Inc. } \\ \text { Hz } & \text { hertz } \\ \text { IBR } & \text { inverter-based resource } \\ \text { IEEE } & \text { Institute of Electrical and Electronics Engineers } \\ \text { kW } & \text { kilowatt } \\ \text { MIRACL } & \text { Microgrids, Infrastructure Resilience, and Advanced Controls Launchpad } \\ \text { MW } & \text { megawatt } \\ \text { NREL } & \text { National Renewable Energy Laboratory } \\ \text { OpenDSS } & \text { Open-Source Distribution System Simulator } \\ \text { PHIL } & \text { power hardware in the loop } \\ \text { PV } & \text { photovoltaics } \\ \text { R\&D } & \text { research and development } \\ \text { ROCOF } & \text { rate of change of frequency } \\ \text { RTDS } & \text { real-time digital simulator } \\ \text { Sandia } & \text { Sandia National Laboratories } \\ \text { SWiFT } & \text { Scaled Wind Farm Technology } \\ \text { UFLS } & \text { under-frequency load shedding } \\ \text { V } & \text { voltwe } \\ \text { VAR } & \text { volt ampere reactive } \\ \text { VRE } & \text { watt-hour (energy) } \\ \text { Wh } & \end{array}$




\section{Executive Summary}

The Microgrids, Infrastructure Resilience, and Advanced Controls Launchpad (MIRACL) project's controls research area aims to quantify and expand the benefits from distributed wind generation assets beyond solely providing low-cost power directly to consumers. Advanced control methods are required to make distributed wind turbines operate more effectively, allowing electric utilities, businesses, and energy consumers to take advantage of the wide range of services from wind turbine systems at the distribution voltage scales. Distributed wind can contribute to the safe and secure operation of the grid by providing services such as voltage regulation, frequency regulation, spinning reserves, and even black start capabilities. In the larger distributed energy resource (DER) context where much of the research has focused on solar technologies, the inertia available in wind technologies has generally not been considered. For wind turbines to provide inertia and other essential grid services in an optimal and expanded way, development and demonstration of control methods and communication interfaces within grid and microgrid frameworks are required.

This National Renewable Energy Laboratory (NREL)-led literature review of DER controls integration, in collaboration with Sandia National Laboratories (Sandia), will help establish a baseline for the controls research under the MIRACL project and develop appropriate scope for distributed wind control functions development to be focused throughout this project. This literature review focuses primarily on the control functions of variable distributed generation, largely pulling from past solar photovoltaics and battery controls works, with a specific focus on applicability for distributed wind energy systems. The goal of this document is to identify a research roadmap based on the open literature and past National Laboratory works to inform advanced wind turbine and power electronics control functions across four use cases identified by the MIRACL project team: (1) distributed wind in isolated systems, (2) grid-connected microgrids (wind-hybrid systems and islanded operation), (3) behind-the-meter distributed wind applications in the power distribution systems, and (4) front-of-the-meter distributed wind applications in the power distribution systems.

Based on this document's historical view of wind turbine and relevant DER controls research, the MIRACL project controls research team identified the following research areas to pursue, which align with the needs of the distributed wind community:

1. Demonstration of distributed wind turbine generators providing a wide range of grid services based on active and reactive power control.

- Essential reliability services such as fault ride through, inertia, primary and secondary frequency response, and black start for resilience will be investigated.

- Assessment will be conducted for the most common forms of distributed wind technologies: stall-regulated to active pitch control, and Type 3 and Type 4 turbines.

2. Demonstration of aforementioned advanced controls for grid support capabilities will be applied across the different applications of distributed wind use cases, from grid-connected, microgrids, and isolated, including transitions between these states as appropriate. 
- Especially for distributed wind turbine in microgrids, studies will include investigating transitions (utility grid-connected to islanded mode, and vice versa) in a seamless (ride-through) manner.

3. Development and demonstration of controls for hybrid distributed wind turbine and battery storage, most specifically with direct current (DC) coupling to take advantage of existing advanced power converter technology that is already integrated into the wind turbine generator. In the hybrid wind farm setup, active load control will also be considered to support higher contributions of wind in isolated grids.

4. Implementation of expanded testing infrastructure at NREL's Flatirons Campus (previously known as National Wind Technology Center) and Sandia's Scaled Wind Farm Technology (SWiFT)/Texas Tech University field and power hardware-in-the-loop test sites, allowing for expanded testing of potential grid support services from distributed wind. Scenarios of assessment will also include distribution systems with high renewable energy contributions, as well as weak rural grids.

All of these studies will be documented with relevant results and findings. 


\section{Table of Contents}

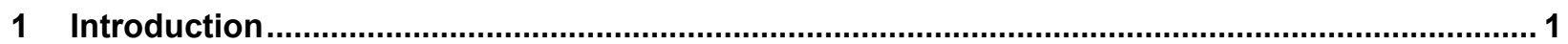

1.1 Control Functions Relevant to MIRACL Use Cases............................................................ 1

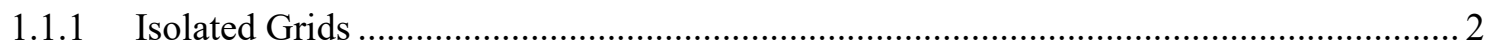

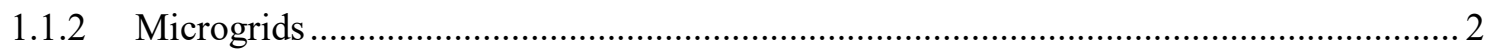

1.1.3 Behind-the-Meter Deployments in Distribution Systems ........................................... 3

1.1.4 Front-of-the-Meter Deployments in Distribution Systems.......................................... 4

1.2 Control of Inverter-Based Resources and Services: Philosophy ............................................... 4

1.3 Microgrid Control Initiatives: Overview......................................................................... 7

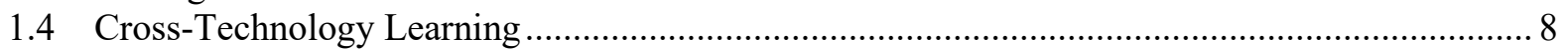

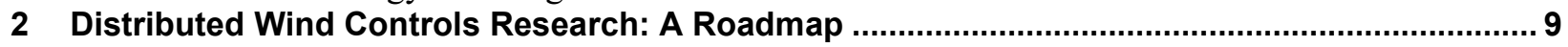

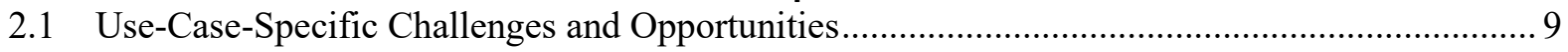

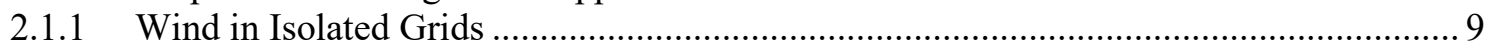

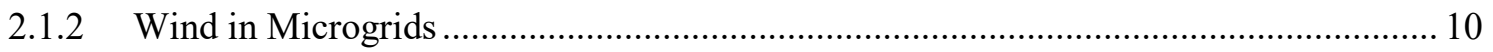

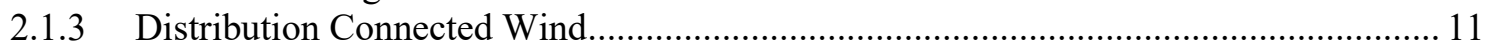

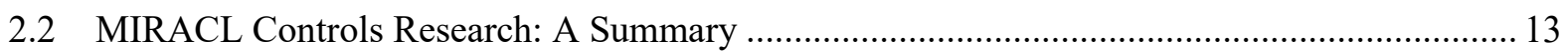

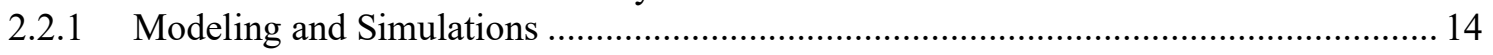

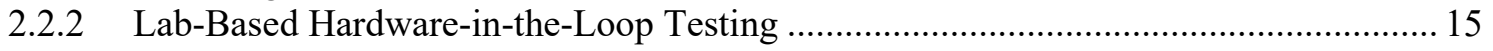

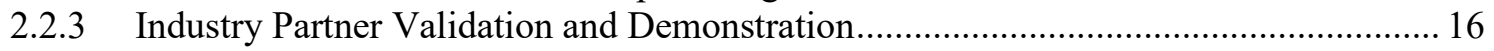

2.2.4 Simulation Scenarios and Metrics Evaluated .............................................................. 18

3 Grid Integration and Controls Research for Microgrid and Distribution Grids ........................ 20

3.1 Background: Increasing Levels of Variable Renewable Energy.............................................. 20

3.2 Quantifying Higher Wind Penetrations and Opportunities ................................................. 20

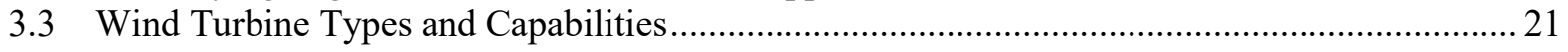

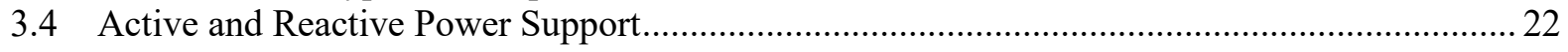

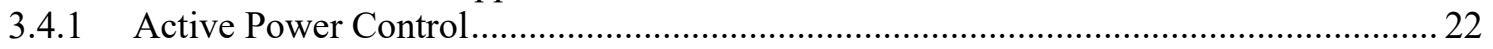

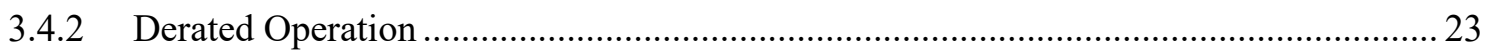

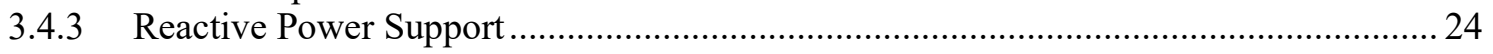

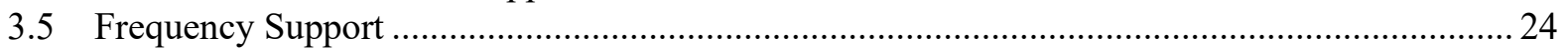

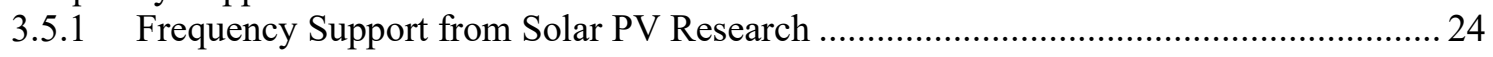

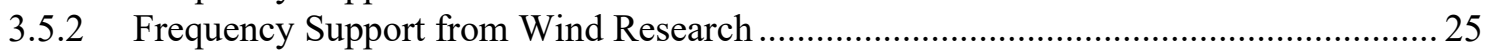

3.5.3 Inertial Support for a Grid with 100\% Inverter-Based Resources ............................... 26

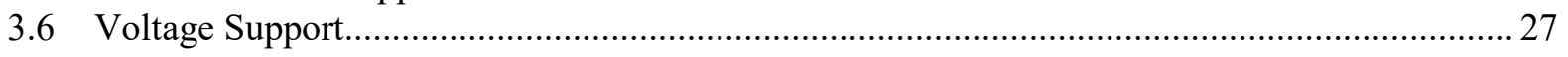

3.6.1 Solar PV Inverter Control - Power Factor, Volt/Var and Volt/Watt control ................ 28

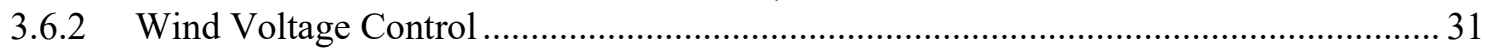

3.7 Power System Restoration Using Variable Renewable Resources .......................................... 32

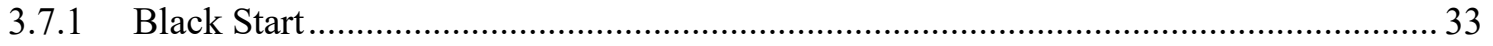

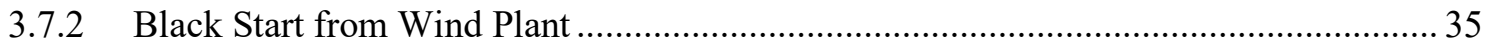

3.7.3 Energization Sequence: System Restoration ........................................................ 35

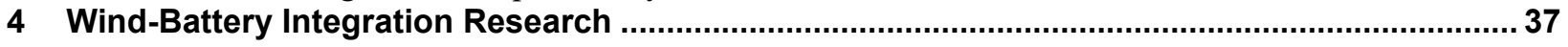

4.1 Wind-Battery Hybrid Grid Services................................................................................... 37

4.2 Reactive Power and Voltage Support.......................................................................... 38

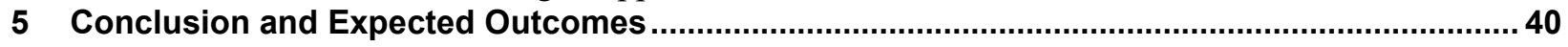

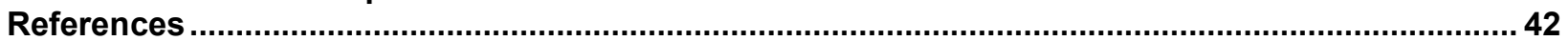




\section{List of Figures}

Figure 1. Microgrid use case: commonalities and uniqueness with other use cases............................... 9

Figure 2. Relationship between transition and dispatch functions (IEEE 2017) ..................................... 11

Figure 3. An overview of MIRACL distributed wind controls research and their relationship with various grid services, use cases, and relevant test systems (DG: distributed generation; FIC: Flatirons

Campus; P\&Q:Real and Reactive Power ; SNL: Sandia National Laboratories) .................. 13

Figure 4. NREL Flatirons Campus with DERs modeled in MATLAB Simulink.................................... 15

Figure 5. Active power control functions (UVIG IEEE 2009) .......................................................... 23

Figure 6. Hz-watt control of smart inverter (solar PV) to provide frequency response........................... 25

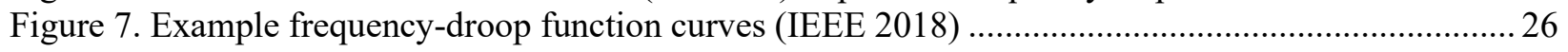

Figure 8. Virtual oscillator control for multiple IBRs (Lu et al. 2019) .................................................. 27

Figure 9. IEEE 1547 evolution informed by DER interconnection and smart inverter studies (Palmintier

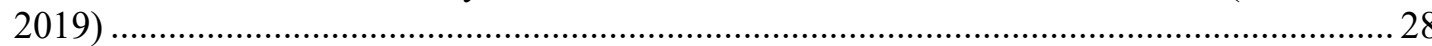

Figure 10. HECO Rule 14H volt-var (top) and volt-watt (bottom) functionalities of smart inverters ....... 29

Figure 11. Mikilua feeder results summary: volt-VAR control functionality improved voltage profile

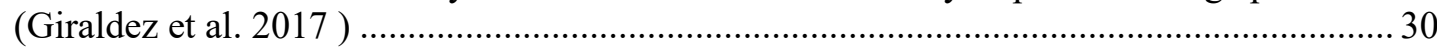

Figure 12. Mikilua voltages: (top) unity power factor; (bottom) volt-VAR .......................................... 31

Figure 13. Reactive power provision for voltage control from different sources (Gevorgian et al. 2019) 32

Figure 14. Restoration process overview, with black start (Adibi et al. 1987) ....................................... 33

Figure 15. Voltage-source converter high-voltage DC topology, an excellent black start resource........... 34

Figure 16. Variable renewable "delta" mode for active power control for frequency support during

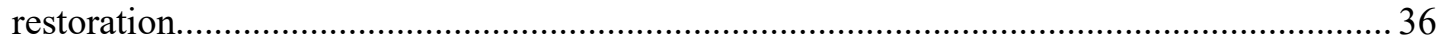

Figure 17. An illustration of various hybrid connections of battery and renewables (Denholm 2017) ...... 38

\section{List of Tables}

Table 1. Available DER Devices for Distributed Wind Lab Testing at NREL and Sandia...................... 15

Table 2. Candidate Real-World Reference Systems for Industry Demonstration ................................... 17

Table 3. Wind Turbine Type and Control Capabilities............................................................................ 21 


\section{Introduction}

Many distributed wind turbines were originally deployed to solely provide energy to their connected distribution systems. As the contribution from distributed wind grows, the need for distributed wind turbines to provide additional grid services and support grid stability will be important. As a generation source with many unique characteristics employing mechanical and solid-state power electronics technologies, wind generation can allow for additional benefits to a power system beyond solely providing energy to the system, such as enhancing grid reliability and resilience and lowering production costs and electricity price.

One of the key Microgrids, Infrastructure Resilience, and Advanced Controls Launchpad (MIRACL) objectives is to expand the understanding and documentation of active control capabilities of different distributed wind technologies and help address integration challenges of wind integration on weak and isolated energy networks. This document outlines a literature review of distributed generation integration (including variable renewable resources and battery storage) and grid support research. A specific focus is opportunities for advancing and documenting expanded grid support from distributed wind across the four use cases: distributed wind in isolated grids, distributed wind in microgrids, behind-the-meter distributed wind turbines, and front-of-the-meter distributed wind turbines.

\subsection{Control Functions Relevant to MIRACL Use Cases}

Traditionally, distributed wind deployments focus on maximizing annual energy production (AEP). Distributed wind control typically utilizes mechanical aspects of the turbine such as rotor speed and pitch as variables to control and maximize the power output. Many modern distributed wind turbines interconnect to the external power system through advanced power electronic interfaces, which allows additional control over the characteristics of the distributed wind system. The coupling of the mechanical and electrical characteristics of a distributed wind system through the inverter and advanced controls methods enables improved control that is expected to increase reliability and allow for greater benefits than previously expected from distributed wind in a power system. However, improved forecasting of wind resources, especially at a higher spatial resolution relevant to distributed wind installations, will be required to better realize the aforementioned benefits of distributed wind systems.

There are two dominant distributed energy resource (DER) control functions applicable to distributed wind controls: grid-following and a grid-forming operational modes. In a nutshell, both functions relate to voltage and frequency regulation for meeting local grid codes and stability standards. Grid-following mode follows a control signal from the grid through real and reactive power changes, whereas grid-forming mode enables DERs to set the voltage and frequency. The control methodology used in a DER and distributed wind turbines is reliant upon the composition of the connected power system and the amount of available wind resource. To align the controls research with specific system needs, the MIRACL project defines a set of four use cases for distributed wind deployments: 
- Use Case 1: isolated grids

- Use Case 2: microgrids

- Use Case 3: behind-the-meter deployments in distribution systems

- Use Case 4: front-of-the-meter deployments.

Operating a power system is a careful balancing act requiring generation to provide many ancillary services, which are typically provided by conventional generation sources. Although distributed wind turbines traditionally do not provide grid services, most are technically capable, and this capability is now required per the recent revision to the Institute of Electrical and Electronics Engineers (IEEE) 1547-2018 standards. With the trend toward higher contributions of variable generation displacing fossil-based generation sources, these functions will be increasingly requested from distributed wind turbines deployed across the four use cases. These challenges will be exacerbated compared to a typical interconnected power system in isolated grids (Use Case 1). Isolated grids typically possess higher contributions of variable renewables and a limited number of flexible resources, and the limited geographic diversity of the variable renewables will exacerbate the impact of their variability. To support these higher contributions of wind, the services required from distributed wind turbines in the future will be, at a minimum:

- Power dispatch and curtailment

- Power factor power support

- Voltage support

- Frequency support

- Voltage and frequency ride through

- Black start capability.

\subsubsection{Isolated Grids}

Isolated grids remain electrically independent of a bulk power grid. They may consist of several different generation technologies (wind, photovoltaics [PV], diesel), storage (battery, thermal, mechanical) and system controls. Systems with high contributions of wind often include an advanced level of supervisory control.

- Technical characteristics: isolated grid, multi-DER, higher variability, potentially include storage and active load control, stricter demands for maintaining stability (as no dependence on the larger grid).

- Financial characteristics: the need for remote power is more dependent on the cost of imported fuel combined with its transport and storage. Reliability, resilience, and fuel security become more significant) considerations.

- Market characteristics: there is a lack of structured markets for isolated, remote, and/or temporary communities, utilities, or state or federal government facilities.

\subsubsection{Microgrids}

A microgrid is a group of interconnected loads and DERs within defined electrical boundaries that can operate either connected or disconnected ("islanded") from an external grid. It may consist of several different generation technologies, controllable loads, and storage systems (Ton and Smith 2012). System controls often include a hierarchical strategy, primary-level control 
within the DERs including fast controls to local events, a secondary control at the microgrid level for overall DER coordination, and optimal DER dispatch. Tertiary controls are used in gridconnected mode for coordination and dispatch optimization with the larger grid (including coordinating with multiple microgrids). Example systems range from small backup power systems using single small wind turbines to relatively large systems such as those for military bases and communities employing multiple distributed wind turbines. Islanded mode is typically used for backup power during a disruption or to shed load when required as a grid service. One critical function for closed transitions is a stable transition between grid-connected and islanded mode, and the ability to black start for open transitions.

- Technical characteristics: able to operate in both grid-connected and islanded mode, multi-DER, higher variability, potentially include storage and active load control, stricter demands for maintaining stability (as no dependence on the larger grid).

- Financial characteristics: high-reliability system to limit financial impacts of an outage, reduce fuel usage during islanded operations.

- Market characteristics: communities/institutions needing energy security in the event of a grid outage.

A microgrid typically requires two main control modes: grid-connected and islanded mode. The role of distributed wind in such modes could be:

- In grid-connected mode, a wind turbine is traditionally used to offset energy purchased from the utility, providing economic benefit to the turbine owner. In some high-windcontribution systems and energy markets, the distributed wind turbine system will be requested or required to provide grid services, including frequency/voltage stabilization, to the connected utility.

- In islanded mode, a wind turbine is typically used to reduce fuel consumption by supplementing/offsetting generation from fossil-based generation. A distributed wind turbine, along with other DERs, will need to sense the disconnect from the external grid and switch operating modes to provide expanded support and receive control requests from the local microgrid controller; these capabilities are required for DERs per IEEE 1547-2018.

\subsubsection{Behind-the-Meter Deployments in Distribution Systems}

Behind-the-meter wind turbines are systems that are always connected to the grid behind the utility meter and are typically directly connected to load in the distribution systems, including net metering (for the purposes of this document and MIRACL research more broadly, islandable systems that are behind the meter are considered under Use Case 2: microgrids). These systems could be made up of several different generation technologies and storage with a goal to better manage meter-level energy usage, including potentially auxiliary services, even if those are primarily focused on addressing behind-the-meter energy quality. These systems may include some level of supervisory control to address/direct specific operational considerations, though utilities and system operators frequently do not have good visibility over the individual DERs (including distributed wind) behind the meter. The utilities and operators often only have information about net-metered load (that includes the contribution of DERs, and hence DER 
outputs are masked), unless they get access to such data through inverter companies or installers. System configuration and size can vary greatly, from a single turbine to relatively complex power systems that could include hybrid distributed generation and storage technology that provides better control of energy draw from the utility.

- Technical characteristics: currently provide energy with limited grid services, behind the meter, remote/virtual net metering, not typically regulated/controlled by utility and markets.

- Financial characteristics: offset retail rates, peak shaving or demand charge reduction, potential decrease of capacity or other power quality charges, potential green power credits, hedge against potential power cost variability.

- Market characteristics: limited structured markets, to be environmentally responsible, to displace high utility bills, or to hedge against energy costs that are likely to increase in the future.

\subsubsection{Front-of-the-Meter Deployments in Distribution Systems}

Front-of-the-meter systems are always connected to load-serving distribution grids. A front-ofthe-meter distributed wind deployment can serve a larger electric power system and can also participate in the wholesale market as an independent power producer, but is installed at the distribution voltage primarily to serve local loads. Systems could be made up of several different generation technologies and storage, with a goal to provide energy at locations of need while supporting other auxiliary services. Given that they are visible to the utility (metered), they may include some level of supervisory control to address/direct specific operational considerations and are generally dispatched by a relevant utility. Project size can vary greatly from one turbine to multiple turbines, but systems are generally no greater than 20 megawatts (MW).

- Technical characteristics: grid-connected systems, can be metered by utilities/system operators, sometimes connected on weak grids, potential for advanced control

- Financial characteristics: compete with wholesale rates, ancillary service markets/support, aggregator or cost-of-service tariff, potential green power credits, provision of capacity in wholesale market through direct participation, aggregator or costof-service tariff hedge against potential power cost variability

- Market characteristics: utilities wanting resource diversity, can be owned by the utility or an independent power provider, may require implementation under the Public Utility Regulatory Policies Act, and can be a hedge against energy costs that are likely to increase in the future.

\subsection{Control of Inverter-Based Resources and Services: Philosophy}

DERs are generally connected to the power systems through power electronic interfaces. Depending on whether the DER is a direct current (DC) (e.g., battery, solar PV, fuel cells) or alternating current (AC) (non-dispatchable wind turbines, dispatchable small hydro and gas turbines) source, and whether the interconnecting grid is an AC or DC system, appropriate topologies and combinations of converters (DC-DC) and inverters (DC-AC) have been used in practice (Olivares et al. 2014). 
For wind turbines, power electronics (see Table 3 for wind turbine types) are used in Type 3 (doubly fed induction generator [DFIG] with rotor-side inverter) and Type 4 (full-power converter, with a rotor-side AC-DC converter and grid-side DC-AC inverter linked through a DC capacitor) wind turbines, thereby offering them a way to provide real and reactive power controlling capability. The purpose of power electronics in a Type 3 wind turbine is to control the rotor current, which provides regulation of the output power and voltage for a wider range of input wind speeds ( $\pm 30 \%$ slip speed) and respond to grid-side disturbances or reliability needs. The Type 4 wind turbine control is much more involved and is decoupled from the main grid through back-to-back power converters. The rest of this section will focus on summarizing the overall control philosophy in a grid with power-electronic-interfaced resources.

The controls at a power-electronics-interfaced wind, solar, or energy storage system could serve two overarching purposes: (1) ensuring a reliable interconnection of inverter-based technology at the point of interconnection at the grid for one of the mentioned Use Cases 1-4 and (2) ensuring grid stability as a result of the interaction of inverter-based resources with the grid under myriad grid disturbances. Typically, the converter that connects the DER to the grid (grid-side converter) uses a control that uses dual loops (Peng et al. 2019; Blaabjerg et al. 2006), with the inner loop controlling/regulating the converter's current and the outer loop setting a voltage set point based on the needed real and reactive power outputs. There can be many variations to this control loop.

In wind plants, in addition to the real power control through inverters, real power regulation can also be achieved by direct control of the mechanical system (i.e., blade pitch, generator torque/speed, and yaw control) - a feature that is made possible by the presence of rotating mass in the wind turbines. However, the type of control depends on the temporal resolution of the service needed for ensuring grid reliability and stability.

Irrespective of the targeted use cases in the MIRACL project, the services that can be obtained from the controls of DERs can be further classified from a temporal resolution perspective. Typically, stability-related services are at the second and sub-second time scale, and include the following, depending on the type of wind turbine interconnection, which impacts reactive power consumption (Singh, Allen, et al. 2014; Wilches-Bernal et al. 2019; Singh et al. 2015):

- Fault ride-through capability and distributed resource anti-islanding

- Oscillation damping for local mode or inter-area oscillations

- Sub-synchronous resonance and harmonic resonance mitigation

- Converter control mode interaction

- Inertial response for frequency stability (Wilches-Bernal, Chow, and Sanchez-Gasca 2015)

- Transient voltage stability.

Although both wind and solar power plants are interconnected via power electronic converters, the presence of rotating mass with stored energy (Guttromson et al. 2017; Gravagne et al. 2018) adds an additional dimension to the distributed wind energy control research that is worth investigating. It will be interesting to investigate the levels of stored inertial energy available 
from different sizes and types of distributed wind resource and quantify both positive and negative impacts. One of the positive impacts from using wind plants is providing synthetic inertia (primary fast frequency response) by using its stored energy in the rotors and the avoidance of pre-curtailment, in comparison to a solar PV plant, which has to provide a headroom and thereby curtail some energy. Negative impacts could be quantified in terms of loading on the wind turbine blades and overall structure to provide inertial response. There are works in the open literature that have also looked to exploit the DC link capacitor between the DER and the inverter to extract short bursts of stored power for frequency and voltage control.

Services that can be provided from DER controls at the seconds to hour time scale include:

- System reliability (load-serving capability)

- Frequency response (secondary and tertiary frequency response services)

- Voltage regulation (steady-state American National Standards Institute [ANSI] voltage limits).

These services could be thought of as steady-state or quasi-steady-state (with some grid dynamics) grid services, compared to the stability related in the transient time scale.

For constant power factor, volt-volt ampere reactive (volt-VAR) (achieved through reactive power control of converters) and volt-watt (achieved through real power curtailment, especially for voltages greater than the ANSI limit of 1.05 per unit) may be performed. For frequency regulation, $\mathrm{MW}$-hertz $(\mathrm{Hz})$ (real power control through converter control) can be performed. Note that the MW-Hz control in the lower temporal scales (few seconds to minutes) is different than the MW-Hz control in higher temporal scales. The inertial response or primary fast frequency response is typically achieved in the first few seconds of the system disturbance to reduce the frequency nadir and rate of change of frequency, much like the natural inertial and governor response provided by the synchronous generator. The type of $\mathrm{MW}-\mathrm{Hz}$ control in the steady-state or quasi-steady-state domain involves secondary (automatic generation control for regulation at 4-6 s) and tertiary (reserve procurement) controls. Depending on the use case, control signals in the steady-state domain are typically initiated by a centralized system dispatcher or optimizer (e.g., a centralized grid control center, distribution management system, or microgrid controller) (Olivares et al. 2014).

The stability and steady-state control strategies outlined here apply for a typical AC grid and normal operating conditions. Special cases of grid type or system conditions will incur additional controls, some of which include: (1) a purely DC grid or a coupled AC-DC grid and (2) system restoration after a brownout or a blackout (i.e., black start capability or aiding restoration process). The latter situation will require inverter-interfaced resources to be connected in a gridforming mode to provide voltage and frequency set points to the grid. Typically, the inverters are connected in a grid-following or supporting mode, where they follow real and reactive power command signals to provide frequency and voltage support.

To investigate the implementation of all the aforementioned control strategies and study the impact on system reliability and stability, appropriate tools are necessary. For the distributed 
wind research, the MIRACL project will also improve the state-of-the-art simulation tool development to study the controls. This includes developing co-simulation tools that can study grid events spanning multiple time scales of interest, from seconds to hours.

\subsection{Microgrid Control Initiatives: Overview}

According to IEEE standard 2030.7-2017, a microgrid is a system that can manage itself, operate autonomously or grid-connected, and connect to and disconnect from the main distribution grid for the exchange of power and the supply of ancillary services. A microgrid can provide increased reliability and resilience to the local energy supply (Milligan 2018). As electric power systems evolve from synchronous generator-dominated systems to inverter-dominated ones, distributed generation, including microgrids, must operate in a more active way to support electric power system stability.

A microgrid retains many features of the bulk grid but at smaller scales, which are commonly managed through a microgrid controller. Power system operation is an intrinsic feature of the microgrid control system, which attempts to balance load with generation considering interoperability and constraints of the subsystems comprising a microgrid. An overview of research and development (R\&D) activities encompassed by U.S. Department of Energy (DOE) microgrid controller initiatives was summarized in a recent article (Ton and Reilly 2017).

With increasing contributions of DERs and microgrids in the bulk power system, utilities are gradually demanding two-way interaction of microgrid control systems and connected DERs to share the benefit and burden of intricate generation and load balancing. Microgrids are governed by the same set of standards and codes as other DERs. An overview of current grid integration, interconnection standards, and emerging solutions, with a focus on storage plus solar PV integration, is summarized in Horowitz et al. (2019). Typical control strategies for microgrids involve a hierarchical control paradigm involving primary, secondary, and tertiary controls (Bidram and Davoudi 2012). Primary control basically involves local DER-level control using local measurements. Secondary controls will be performed at the microgrid level to dispatch and control various DERs to achieve microgrid operational objectives (in grid-connected and islanded modes). Tertiary controls will be used in the grid-connected mode and will utilize the grid-wide control optimization strategies to ensure grid stability, reliability, and economic operation. These are outlined in the recent IEEE 2030.7-2017 - IEEE Standard for the Specification of Microgrid Controllers (IEEE 2017).

Distributed wind brings additional complexity to controls in a microgrid, as wind energy can be a less predictable resource at the local level than solar, and wind turbines include complex mechanical components that are monitored and controlled. An additional set of challenges starts to emerge as DER contribution levels advance from low to high levels. Penetration levels of renewable energy are a moving target informed by confluences of technology advances, knowhow, and informed choices we make about our energy services and uses. To understand the impacts and study the microgrid controls that include distributed wind resources, some of the control strategies delineated in Sections 3 will be adopted. 
Various tools are being developed to support microgrid planning, design, and control across various national laboratories through DOE support. The definition of a microgrid has evolved over time; accordingly, the tools and methods employed must adapt to provide capabilities and features such as grid services (e.g., voltage support, VAR support, inertial response, primary frequency response), which are not commonly considered.

\subsection{Cross-Technology Learning}

Some of the control functions important for distributed wind share some commonality with functions explored in other technology spaces, such as solar PV and battery energy storage systems (BESS). Hence, in this section, we briefly review literature from solar PV and other technologies for applicability to distributed wind. More detailed review of such cross-technology control experiments, including past and current National Renewable Energy Laboratory (NREL) studies, is provided in later sections. Sandia National Laboratories (Sandia), a project partner of MIRACL, has done some work on grid support functions and power-hardware-in-the-loop (PHIL) testing, especially for the solar PV control case. Fast-frequency support functions (Elkhatib, Neely, and Johnson 2017) and ancillary service capabilities of residential and small commercial inverters (Gonzalez, Johnson, and Neely 2015) are equally relevant for the MIRACL project. Some grid support functions such as volt-VAR curves and extremum seeking control have been evaluated (Darbali-Zamora 2019) for solar PV inverters and could be applicable for distributed wind control.

DC power converter-based control can integrate/sum generations from all variable renewable energies (VREs) and utilize a single point of DC/AC conversion along with a smart inverter function. An example of such capabilities was demonstrated recently (Zeng et al. 2019) with a four-port DC-DC converter for a stand-alone wind and solar PV system. An important aspect of such a converter is that it may maintain a constant DC-link voltage even with the variable nature of renewable energy generators. This is an important function to aspire to for performance and reliability of a grid-connected inverter.

With an example distribution circuit test bed at the Distributed Energy Technologies Laboratory (DETL) at Sandia, a team demonstrated control function for voltage regulation using DER power factor, volt-VAR, and extremum seeking control methods (Johnson, Gonzalez, and Arnold 2017). A voltage regulation within stipulation limits at the various nodes of a microgrid could be a cross-technology control function that the MIRACL project could investigate. Any structurally similar control function may be transpired across technologies to make VREs (distributed wind) smarter. 


\section{Distributed Wind Controls Research: A Roadmap}

A wind turbine system has multiple ways of providing various grid services, ranging from physical and synthetic inertial response to real power and reactive power control functions using smart inverters, and can also work in tandem with storage systems to provide essential reliability services. Several of these advanced functions will be discussed in Sections 3 and 4. These advanced control functions will have different values, benefits, and technical impacts across the different use cases introduced in Section 1.1. These use cases present unique challenges as well as opportunities to distributed wind integration, some of which are summarized in the following sections. Under MIRACL controls research, the controls team intends to combine behind-themeter and front-of-the-meter deployments, as shown in Figure 1, as they will produce largely similar results from a controls perspective. These results will be translated and expanded for the other areas of research under the MIRACL project, such as valuation, modeling, resilience, and cybersecurity.

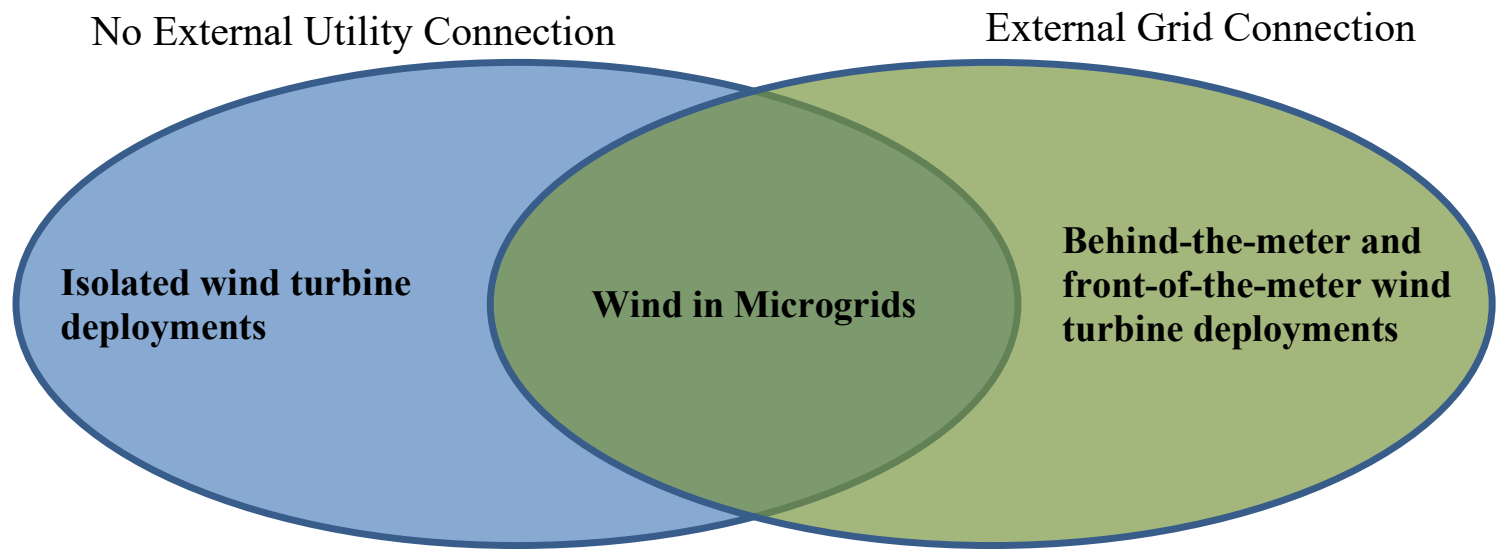

Figure 1. Microgrid use case: commonalities and uniqueness with other use cases

\subsection{Use-Case-Specific Challenges and Opportunities}

The following sections outline various challenges and opportunities identified during background research in an effort to develop a way forward for MIRACL advanced controls research.

\subsubsection{Wind in Isolated Grids}

- Challenges: High-wind-contribution isolated systems such as in Alaska experience regular, unannounced turbine shutdowns for a variety of conditions, including high wind speed, excess vibration, or just a simple controller reset. Given the size of the isolated grid, these sudden operation events force plant operators to maintain excess spinning reserve, which limits the potential savings that high-wind-contribution systems could provide in isolated systems. Therefore, better forecast integration and look-ahead planning of operational and spinning reserves (for ramping and unannounced contingencies) is needed to minimize such costs.

- Opportunities: In isolated grids, a wind turbine is typically used to reduce fuel consumption by supplementing/offsetting generation from fossil-based generation. As wind resource becomes a higher percentage of the generation capacity, the isolated grid 
owner may require the wind turbine to support grid stability, provide essential grid services, and allow better visibility and control over turbine instrumentation. Integration of storage systems with wind in such isolated systems can help offset such additional reserve cost, as storage could be used to store excess wind (instead of curtailing) and leverage that during such wind-outage or excess down-ramp events. Demand response across various time scales to support daily ramping of wind and even short-duration cycling will also be investigated as a novel control mechanism to support high contributions of wind in isolated grids. Inertial response, in which the wind turbine's active power is varied in proportion to the rate of change of frequency, will have an enhanced value in an isolated grid. According to IEEE 1547, inertial response is not required of turbines in grid-connected mode but is permitted. In isolated mode, inertial response can provide time for the primary generator to come online.

\subsubsection{Wind in Microgrids}

The role of distributed wind controls in a microgrid has several commonalities with isolated and grid-connected use cases, as depicted in Figure 1, and yet has unique needs when it comes to research on islanded-mode operations for ensuring stable and resilient transitions, and secondarylevel microgrid controls that will link the microgrid with the larger grid during connected state.

- Challenges: The research challenges for integrating distribution wind technology in microgrids lie in wind turbine primary controls and their interoperability and communication with the secondary controls of the microgrids. This applies to gridconnected and islanded, as well as during transition periods focusing on how the wind turbines can operate to better support the grid. Another challenge is the need for stable voltage support during disturbances or islanded operation. In the presence of a stable voltage source, typically distributed wind technologies may be connected in a gridfollowing mode. However, with higher penetrations of DERs in grid-following mode, DERs may cut out during faults at same time, creating a large outage. Therefore, for resilience against fault situations and disturbances, as well as supporting $100 \%$ inverter resources-based microgrids, grid-forming controls for distributed wind are being pursued. A relevant challenge will be to operate the distributed wind technology in grid-forming mode and offer stable voltage. This research challenge may also apply to the isolated grid use case. Related challenges will be to utilize inverter-based distributed wind turbine technologies for a larger pool of essential reliability services in the microgrid, such as for supporting the voltage and frequency stability, and providing black start capability. These challenges may require distributed wind to operate stably in grid-forming mode and adhere to synchronization and power-sharing controls via droop-based or virtual oscillator-based approaches.

- Opportunities: Distributed wind deployments in microgrids will benefit from the research covered in the isolated grid R\&D for islanded mode, and the grid-connected controls research during normal grid-tied operation. In both situations, the two important functions the controller needs to handle are transitions and dispatch. Figure 2 presents relationships and interactions between transition and dispatch function in the case of core microgrid control function (IEEE 2017). The transition between the two operating modes can be done in two ways: in a seamless manner (closed transition), or with a shortduration outage before the microgrid is brought back online (open transition). The 
transition from grid-connected to islanded operation is relatively simple and straightforward for a single generation source. When a system consists of many generation, storage, and demand response components needing to transition together, the components of the system must maintain stability to avoid triggering anti-islanding protections during the transition. The anti-islanding protections were designed to ensure that DERs trip offline and do not create an accidental island, but during transition to or from an island scenario, these set points may be too restrictive for the weak power system of the island. Therefore, performing transient studies for the transition to understand the role of distributed wind technology to support the transient stability and stable transition will be interesting. As discussed in previous use cases, using the unique characteristics of wind energy systems to provide a full range of ancillary services, including inertia and black start, and developing advanced wind communication strategies will be relevant high-priority research activities.

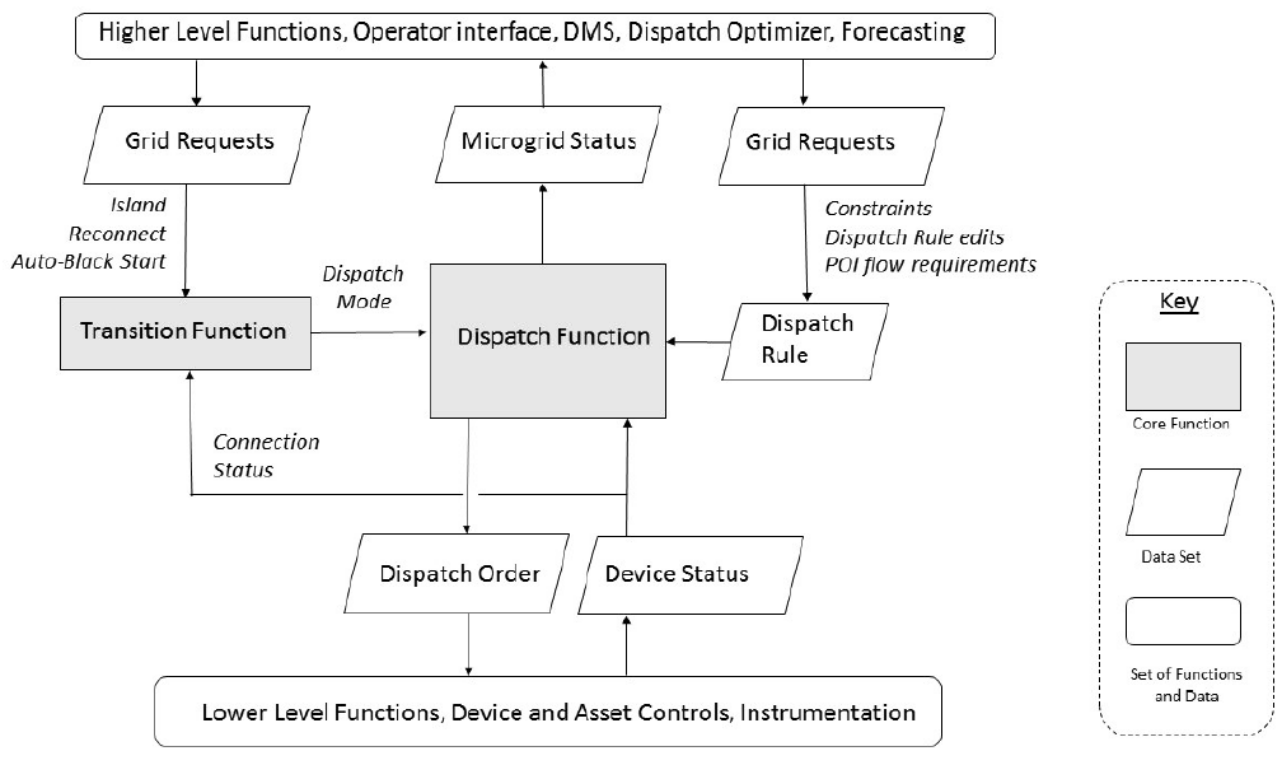

Figure 2. Relationship between transition and dispatch functions (IEEE 2017)

\subsubsection{Distribution Connected Wind}

A distribution-system-connected (both front-of-the-meter and behind-the-meter) distributed wind turbine is traditionally used to offset energy purchased from the utility, thereby providing economic benefit to the turbine owner.

- Challenges: Integrating wind turbines to the distribution grids (either front-of-the-meter or behind-the-meter), especially state-of-the-art Type 3 (converter connected at the rotor side) or Type 4 (full power converter at the stator) turbines, will have impact on the grid's frequency response. With the power converters at the interface, the rotor frequency of a wind turbine is decoupled from grid frequency, and hence they don't inherently provide inertial response that we typically obtain from synchronous generators (inertia and governors). Past works have demonstrated the technical feasibility of providing inertial response or fast frequency response from large utility-scale wind turbines, and such research and demonstration will have to be investigated for the distributed wind 
interconnections at the lower-voltage distribution grids. Another challenge, particularly for behind-the-meter applications, is the general lack of visibility to the utility or system operator, as typically they only have access to net-metered data, where individual DER behind-the-meter is masked.

- Opportunities: In some high-wind-contribution systems and energy markets, the distributed wind turbine system will be requested or required to provide ancillary services to the connected utility. The updated 2020 edition of the IEEE 1547 grid connection standards requires that inverters be able to provide significant grid support services. These regulations have opened up opportunities for developing distributed wind functions and technical capabilities for grid integration. The MIRACL project will explore some of the functions and test them in a hardware-in-the-loop environment at NREL's Flatirons Campus. The control functions to be investigated for a wind turbine connected at the medium- or low-voltage distribution grid are summarized here:

- Power (active and reactive) control for essential reliability services: The control of active and reactive power for essential reliability could be specific to a turbine type and grid connection topologies. For example, scenarios of weak rural feeders will require much more onus on distributed wind to provide grid services than an interconnection at a strong grid. The essential reliability services are of several types, including inertia, frequency response (primary governor droop-based and secondary based on automatic generation control $[\mathrm{AGC}]$ ), voltage or fault ride through, and congestion management, to mention a few. Sections 3 and 4 elaborate on some examples of DERs providing such services. For some wind turbines, such capabilities are inherent in the interconnection standard's requirements, whereas others need to utilize the advance control mechanisms. The advance control of the variable renewable generation always comes at a cost (i.e., the cost of additional controls and the cost of curtailing real power for providing essential reliability grid services). Evaluating and augmenting the external control is an economic question that requires careful weighing of marginal cost and benefits (the benefits being improvement in frequency response, voltage, reactive power support services, reduced network congestion and losses, and reduced curtailment).

- Integrated storage and hybrid wind farm: Although this integration is also applicable to other use cases, the economic value that an integrated storage-wind (hybrid wind) system will have on a distribution grid will be much higher than on an islanded microgrid or isolated grid alone. However, the economic benefit as related to energy resilience may be more valuable depending on the requirements of the system owner. In the latter use cases, the motivation is more for reliability and resilience, whereas in the mainstream grids, the need for distributed hybrid wind can also be motivated by economic reasons. Integration of storage and other DERs with the wind turbine, via different strategies such as AC or DC coupled, will need design and operational investigation to better understand their value and price bids for providing grid services.

- Forecast-based proactive/preventive control: Additionally, an underlying capability needed for enabling grid services from distributed wind is the need for advanced forecasting techniques for higher spatial resolutions (at the distribution feeder and substation levels, including individual meters for some rare control applications). In 
order for a wind turbine to participate effectively in the distribution network or an area electric power system, it is important that the controller of the wind turbine know states of various subsystems that form a wind turbine system and its environment, predict a course of action under a given forecasted operation condition, and pass on information to the upstream network interface (grid). A centralized controller then may make an informed system-level decision and command set points for wind turbines for effective operation under given conditions and constraints. Such a predictive or proactive wind turbine controller with forecast-based intelligent control functions could help wind turbines play their best possible role in the distribution system (or in a microgrid use case).

\subsection{MIRACL Controls Research: A Summary}

In summary, the MIRACL distributed wind research plan aims to lay a foundation for controls research and consequent demonstration of integrating distributed wind resources into the four use cases. The advancements made in DER controls (summarized in Section 3) will be leveraged and adapted for distributed wind use cases. Figure 3 presents a high-level summary of the proposed research activities in this MIRACL distributed wind project funded by the Wind Energy Technologies Office. As seen, the control research is split into four use cases, though there are clear overlaps in the modeling tasks, as learned from previous discussion.

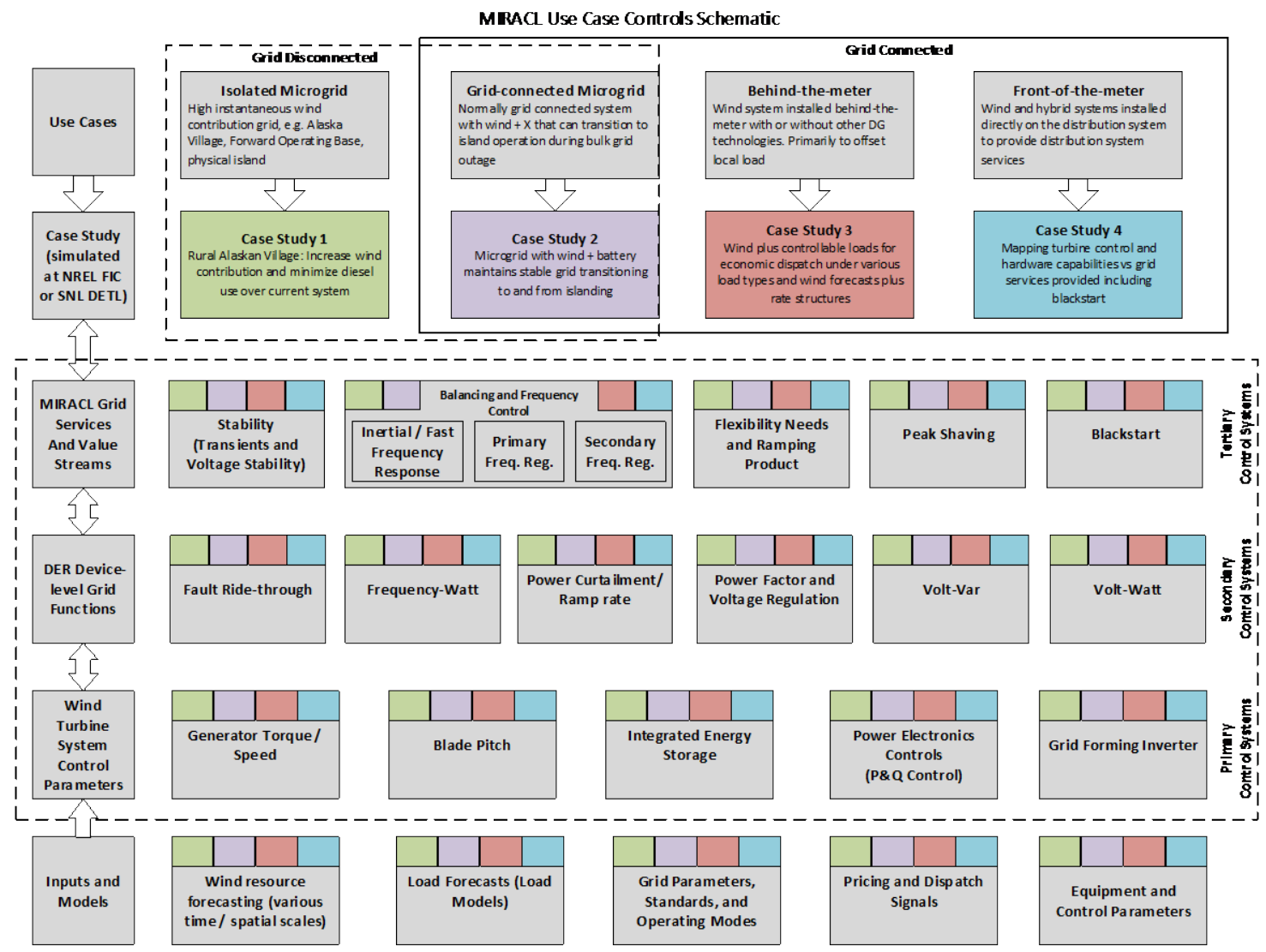

Figure 3. An overview of MIRACL distributed wind controls research and their relationship with various grid services, use cases, and relevant test systems (DG: distributed generation; FIC:

Flatirons Campus; P\&Q:Real and Reactive Power; SNL: Sandia National Laboratories) 


\subsubsection{Modeling and Simulations}

The test systems and scenarios we will use in modeling and simulating each of the use cases will be different, thereby making the modeling and simulation studies interesting. We will be able to understand the role and value of the distributed wind quantitatively in each of these use cases. The various possible grid services and value streams are listed in the third row of Figure 3. Although the majority of those services apply to a grid-connected situation, in isolated use cases, priority might be given to some services more than the others. For instance, in an isolated grid scenario, reliable operation and resilience against disturbances is highly desirable compared to economic dispatch based on look-ahead scheduling. Such advanced predictive planning of energy and reserves from the distributed wind technologies based on look-ahead forecasts maybe more valuable in grid-connected use cases, where we have multiple resources to coordinate with and opportunities for economic utilization of resources.

It should also be noted that some controls are needed at the device level, as listed in the fifth row (primary controls). The secondary control will be one level higher than the primary device-level controls, which are used to optimize the resources and DERs in a microgrid. Tertiary controls will include coordination with a central dispatcher (e.g., markets or utility control center, more applicable to Use Cases 2-4).

The last row of Figure 3 lists the various inputs needed to undertake the research activities, including load and variable renewable time series forecasts, control parameters, and tariff structures relevant to the use cases. These data sets will dictate the scenarios under which simulations may be performed and have direct impact on the value proposition of the distributed wind.

The models will be developed using MATLAB Simulink software to be reconfigured and will represent all four MIRACL use cases. Figure 4 shows an example of current MATLAB Simulink modeling to design, simulate, and validate the NREL Flatirons Campus testing facility. This model will also be applicable to an isolated grid, where the microgrid is not connected to any external voltage source. For grid-connected use cases, the Simulink models will be connected to a larger distribution feeder (either in MATLAB or via co-simulation with distribution system simulation software such as Open-Source Distribution System Simulator [OpenDSS] or GridlabD). We may also investigate the use of PSCAD models to study the transient behaviors and stability in a computational tractable manner, especially studying phenomena related to oscillations in a weak grid, phase imbalances during faults, or distributed wind supporting inrush currents during black start. 


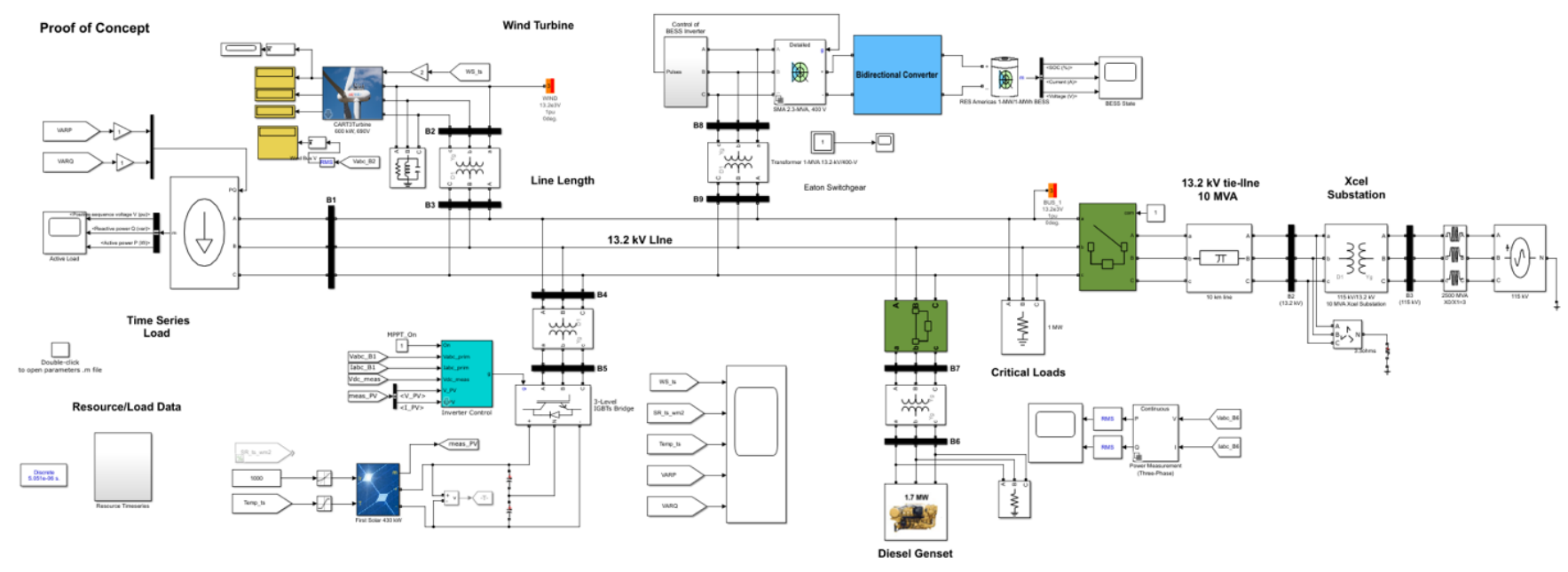

Figure 4. NREL Flatirons Campus with DERs modeled in MATLAB Simulink

\subsubsection{Lab-Based Hardware-in-the-Loop Testing}

In addition to the simulations, we will demonstrate proof of concept in a controlled lab-based hardware testing environment. We will leverage the state-of-the-art testing facility available at both NREL's Flatirons Campus and Sandia's DETL facility; a summary of assets available is shown in Table 1. We will carry out power hardware-in-the-loop testing, leading to field testing of ideas in a controlled environment.

Table 1. Available DER Devices for Distributed Wind Lab Testing at NREL and Sandia

NREL Flatirons Campus (20 MVA a at 13.2-
$\mathrm{kV}^{\mathrm{b}}$ Xcel grid via controllable grid interface)
Sandia Scaled Wind Farm Technology (SWiFT)

DETL microgrid (at 12.47-kV medium-voltage

Hurlwood distribution system)
- CART3 wind turbine (600 kilowatts [kW])

- First Solar 430-kW PV array

- SunEdition 1-MW PV array

- 1-MW/1-MWh (megawatt-hour) RES Americas LG lithium-ion battery (SMA 2.3-MVA, 400-V inverter/charger), connected via 1MVA 13.2-kV/400-V transformer

- Real-time digital simulator (RTDS)/PHIL model of diesel generation (1.7 MW)

- Loads: critical and controllable loads

- Sensing and collection systems

- Distribution wind turbines (upcoming)

a Megavolt-ampere

${ }^{b}$ Kilovolt

c Kilovolt-ampere

d Global Laboratory for Energy Asset Management and Manufacturing 


\subsubsection{Industry Partner Validation and Demonstration}

Eventually, the demonstrations will move toward real-world systems working with industry partners. There are two phases to this effort: desktop simulation and hardware-in-the-loop validation. The real-world systems can be modeled using simulation tools and can be simulated in the NREL/Sandia lab environments using RTDS testing, with the DERs at NREL/Sandia assumed to be connected to one of the nodes at the real-world models. Such system modeling can be done for Public Service Company of New Mexico (PNM1, PNM2, PNM3) feeder models with $>50 \%$ DERs (Sandia), national grid feeder models (Sandia), Saint Mary's microgrid in Alaska (Sandia), Cordova microgrid model in Alaska (Sandia), building group NIRE 540 model (suited for behind-the-meter customer-sited distributed wind interconnection testing), Commonwealth Edison's (Illinois) Bronzeville Community microgrid model (NREL) (Bahramirad et al. 2018), and Modified Banshee microgrid model (connected with NREL PHIL testing node) (NREL 2017). Additionally, thanks to the industry advisory board members meeting in March 2020, there are several other candidate systems, summarized in Table 2, where we will explore performing field demonstration, starting with modeling their systems at Sandia/NREL, and developing a field test plan based on simulations and lab testing. 
Table 2. Candidate Real-World Reference Systems for Industry Demonstration
System Name
Description

Joint Base Cape Cod Otis U.S. Department of Defense Strategic Environmental Research and Development Program/Environmental Security Technology Certification Program (SERDP/ESTCP) microgrid

\begin{tabular}{|c|c|}
\hline $\begin{array}{l}\text { Lake Region Community Hybrid project (electric } \\
\text { cooperative) }^{\mathrm{a}}\end{array}$ & $\begin{array}{l}\text { Wind-solar hybrid system developed by } \\
\text { Juhl in Pelican Rapids, Minnesota }\end{array}$ \\
\hline $\begin{array}{l}\text { lowa Lakes Electric Cooperative distribution wind } \\
\text { farms }\end{array}$ & $\begin{array}{l}\text { Multi-megawatt wind plants serving } \\
\text { industrial loads (ethanol plants) }\end{array}$ \\
\hline Buckland, Deering, and Kotzebue, Alaska ${ }^{c}$ & $\begin{array}{l}\text { Wind-diesel-solar-battery hybrid system } \\
\text { (isolated Northwest Arctic communities) }\end{array}$ \\
\hline Kodiak Electric Association, Kodiak, Alaska ${ }^{d}$ & $\begin{array}{l}\text { Cooperative with }>98 \% \text { renewable: hydro, } \\
\text { wind, flywheel, diesel }\end{array}$ \\
\hline Fire Island wind on Railbelt grid & $\begin{array}{l}\text { 17.6-MW (11-turbine) independent wind } \\
\text { plant near Anchorage, Alaska }\end{array}$ \\
\hline Igiugig, Alaska ${ }^{e}$ & $\begin{array}{l}\text { 35-kW run-of-the-river turbine, smart grid } \\
\text { and electric battery }\end{array}$ \\
\hline City of Summerside, Prince Edward Island ${ }^{f}$ & $\begin{array}{l}\text { Grid-connected microgrid with wind, solar, } \\
\text { battery, and diesel, advanced controls }\end{array}$ \\
\hline Old Crow, Yukong & $\begin{array}{l}\text { Grid-forming when running only on PV and } \\
\text { battery in summer }\end{array}$ \\
\hline Colville Lake, Northwest Territories ${ }^{h}$ & Solar-diesel-battery system with live data \\
\hline Gull Bay First Nation, Ontarioi & Solar-diesel-battery system \\
\hline Homer Electric Association, Homer, Alaska ${ }^{j}$ & $\begin{array}{l}\text { Railbelt community with diesel and battery } \\
\text { for grid support when islanded }\end{array}$ \\
\hline National Grid Nantucket BESS ${ }^{k}$ & $\begin{array}{l}\text { Battery storage plus diesel generator for } \\
\text { grid loss "resiliency" }\end{array}$ \\
\hline Tullahennel, Ireland' & $\begin{array}{l}\text { Wind with integrated battery storage for } \\
\text { grid services/data centers }\end{array}$ \\
\hline $\begin{array}{l}\text { PJM PV + battery for black start services R\&D } \\
\text { project }^{\mathrm{m}}\end{array}$ & $\begin{array}{l}\text { Solar Energy Innovation Network (SEIN) } \\
\text { project on PV + storage for black start }\end{array}$ \\
\hline PJM Philadelphia Navy Yard Microgrid Project ${ }^{\text {n}}$ & $\begin{array}{l}\text { Natural gas peakers, rooftop solar, fuel } \\
\text { cell, battery redevelopment }\end{array}$ \\
\hline
\end{tabular}

${ }^{a}$ https://www.juhlcleanenergyassets.com/projects/

b https://www.ilec.coop/renewable-energy

${ }^{c}$ https://www.ktuu.com/content/news/Buckland-sets-a-milestone-for-rural-energy-capabilities-with-new-Li-ion-battery540800061.html

d https://kodiakelectric.com/about/

e https://microgridknowledge.com/tribal-microgrids-federal-energy-funds/

f https://www.electricalindustry.ca/changing-scenes/4841-hydro-ottawa-and-city-of-summerside-to-optimizemicrogrids-with-ai

${ }^{g}$ https://www.bba.ca/wp-content/uploads/2019/07/oldcrow-en-spread-web.pdf

$\mathrm{h}$ https://www.ntpc.com/smart-energy/how-to-save-energy/colville-lake-solar-project 
i https://www.nrcan.gc.ca/science-data/funding-partnerships/funding-opportunities/current-investments/gull-bay-firstnation-diesel-offset-micro-grid-project/22301

j http://www.homerelectric.com/battery-energy-storage-system-bessupdate/?utm campaign=PD BESS\&utm content=119934815\&utm medium=social\&utm source=linkedin\&hss cha nnel=Icp-37845

k https://www.wbur.org/earthwhile/2019/10/08/nantucket-energy-storage-lithium-ion-giantbattery?utm content $=109906049 \&$ utm medium=social\&utm source=linkedin\&hss channel=Icp-37845

I http://www.ionicconsulting.ie/the-first-of-its-kind-tullahennel-wind-farm/

$\mathrm{m}$ https://insidelines.pjm.com/pjm-grant-targets-role-of-solar-storage-in-grid-resilience/

${ }^{\mathrm{n}}$ https://microgridknowledge.com/philadelphia-navy-yard-microgrid/

\subsubsection{Simulation Scenarios and Metrics Evaluated}

Based on Figure 3, simulation experiments for distribution wind research under all four use cases need to be done at varying time scales of controls as needed by the various grid services.

Therefore, the scenarios will include, but are not limited to:

- Active Power Control and Reactive Power Control $(<5 s)$

- Purpose: active power (curtailment, derating [fault tolerant], delta, proportional), reactive power command

- Scenarios: baseline (diesel gen set, no DER control), wind, wind with integrated DCcoupled BESS, wind with AC-coupled BESS, BESS (in grid forming)

- Inertial Response $(<10-20$ s)

- Purpose: inertia support from wind and DERs (to reduce frequency nadir and limit rate of change of frequency $[\mathrm{ROCOF}]$ )

- Scenarios: baseline (diesel gen set, no DER control), wind, wind with integrated DCcoupled BESS, wind with AC-coupled BESS, BESS (in grid forming)

- Primary Frequency Response (governor droop) $(<10-50 \mathrm{~s})$

- Purpose: after initial inertia support, frequency deviations beyond a deadband will be offset by local governor droop (the headroom reserved by active power control [e.g., delta] could be used here)

- Scenarios: baseline (diesel gen set, no DER control), wind, wind with integrated DCcoupled BESS, wind with AC-coupled BESS, BESS (in grid forming)

- Secondary Frequency Response (AGC) - seconds to 5 min and higher

- Purpose: any residual area control error resulting from frequency error from local generation/net-load changes or tie-line deviations will be offset at 4-6-s AGC signals (decided based on area control error and local droop)

- Scenarios: wind, wind + BESS hybrid, microgrid (for $5 \mathrm{~min}$, hours, and days)

- Note: for multi-hour or multi-day simulations, the MATLAB simulation models will need to be co-simulated with market clearing process (economic dispatch and unit commitment models)

- Voltage Support (all time scales, especially $<10$ s)

- Purpose: transient response (faster settling of voltage transient or quicker recovery of voltage sag after fault), fault ride through, providing inrush currents for black start, 
voltage disturbance at point of interconnection or in a "weak" grid, maintain local point-of-connection nodal voltage or remote nodal voltage at some set point.

- Scenarios: baseline (diesel gen set, no DER control), wind, wind with integrated DCcoupled BESS, wind with AC-coupled BESS, BESS (in grid forming), "weak" grid.

Metrics of interest to be evaluated in simulations as well as field testing studies will include:

- Stability and Controllability: rate of response, device level bidirectional communication latencies $(<10-50 \mathrm{~ms})$, time to offset transients and reach stability, power sharing as per command, black start capability and time taken to synchronize $(<1 \mathrm{~s})$, battery fade time (percentage time state of charge hits the limit), inertial response time, eigen values and dominant modes, droop parameters, ramp controllability, stable voltage source (gridforming mode).

- Reliability: AGC (control performance standard), frequency response (nadir, ROCOF), ramping capability, voltage regulation and control (deviation from ANSI limits, transient oscillations, slow voltage recovery [sag]), real power curtailment, supply inrush current.

Economics: Peak shaving, pay for performance (MW mileage in response to AGC or area control error signals [i.e., higher-quality regulation services]), following economic dispatch, and lower load shedding or renewable curtailments. More economics metrics related to market price impacts, line flow congestion, regulation up/down, spinning/non-spinning reserves will require co-simulating higher time resolution control models with production costing or unit commitment/economic dispatch process such as utilizing DOE Hierarchical Engine for Largescale Infrastructure Co-Simulation (HELICS) platform. ${ }^{1}$

${ }^{1}$ https://helics.org 


\section{Grid Integration and Controls Research for Microgrid and Distribution Grids}

\subsection{Background: Increasing Levels of Variable Renewable Energy}

Integration of VRE into the power system traditionally depended on the conventional spinning (or dispatchable) reserve. VRE was considered as a negative load into the power grid. At a small contribution level of VRE, the spinning reserves can easily absorb variations in loads. However, the issues become pronounced at a high level of contribution. A systematic study of how much wind energy power can be reliably integrated into the U.S. power grid began with Eastern and Western Wind Integration Data Sets, which led to development of the Wind Integration National Data Set (WIND) Toolkit (Draxl et al. 2015). NREL has done one of the largest such regional studies to date. The three-phase Western Wind and Solar Integration Study (NREL 2020b) was commissioned in 2007 to understand the costs and operating impacts resulting from the variability and uncertainty of wind, PV, etc. on the Western Interconnection. Without a significant grid infrastructure upgrade, the three-phase research (2007-2015) found that it is operationally feasible to accommodate about 30\% wind and 5\% solar energy in the West (GE Energy 2010). A similar study at 5-minute resolution on the power grid of the eastern United States revealed that the grid can accommodate upwards of $30 \%$ wind and solar/PV power (NREL 2020a). A high contribution of VRE will have an impact on the way spinning reserve and regulation services are procured and will necessitate an increased coordination among available flexible generators in the system operator footprint (independent system operators/regional transmission organizations) (Hobbs et al. 2018; Huang, Krishnan, and Hodge 2018). The World Bank's Energy Sector Management Assistance Program has a recent summary (ESMAP 2019) regarding grid integration requirements of VRE.

These system-level studies have provided important insights into the planning of VRE into a larger generation portfolio. However, various technical and economic issues start to emerge at different scales of integration. At the distributed scale or local level, the wind turbine needs to shoulder its own variability to provide headroom for coordination with other subsystems. In weak grids, wind integration research needs to consider voltage regulation functionality and solutions to counter the lowering of system inertia (caused by more power-electronics-based DER integration). An example of voltage control is the control at the DC link of a Type 4 wind generator (Singh, Muljadi, et al. 2014) operating in weak-grid systems (Yuan et al. 2009).

\subsection{Quantifying Higher Wind Penetrations and Opportunities}

The contribution level of VRE in an isolated power system can be characterized utilizing various metrics. A pair of metrics could be peak instantaneous power and average annual energy with reference to the load on the power system or microgrid. The primary, or grid-forming, generator in an isolated operation is normally a diesel genset. In a grid-connected microgrid, the grid can be viewed as a primary, or grid-forming, asset.

- Annual VRE contribution level = Percentage of the load's annual energy $(\mathrm{kWh})$ met by VRE 
- Instantaneous VRE contribution level = Percentage of the load's instantaneous power $(\mathrm{kW})$ met by VRE at any point in time.

The annual average percentage of the load served by the renewable energy-based generators within the boundary of the grid balancing area largely characterize the contribution level of VRE. Such metrics are also defined for each technology and are sometimes referred to as the load ratios of the technology (e.g., wind, solar PV) comprising the system. As the contribution level of VRE trends to medium and high (Kroposki et al. 2017), a separate set of economic and engineering challenges arise to adhere to the quality assurance framework for microgrids or isolated grids (Baring-Gould et al. 2016).

In such high-VRE penetrations, a wind turbine in a microgrid, especially for islanded operation, can harness rotor inertia (Muljadi et al. 2012) and an integrated storage on the DC link (Jiang and Yu 2008; Miller 2014; Pokharel, Ojo, and Balogun 2015) to add value to the system. The gridside inverter can be made to integrate with storage to provide additional grid services. These are some features in which power electronics and mechanical inertia control can work together to provide fast frequency response in the wind turbine. These features may find a significant value at distributed scale or in a microgrid environment. Again, the value may well also depend on the contribution level of VRE in the local power system.

\subsection{Wind Turbine Types and Capabilities}

Wind integration into the power system depends also on the wind turbine type. There are four different generator topologies used in wind turbine applications (Hansen 2012), summarized in Table 3. These generator topologies for utility-scale application are classified as Type 1 through Type 4. They range from fixed-speed rotors (Type 1) to variable-speed rotors that utilize full back-to-back power converters (Type 4). In conventional (generic) Type 3 and Type 4 machines, the rotor speed/frequency is normally detached from the grid frequency. However, an advanced control system can utilize an existing (Type 3) and/or additional feedback loop (for Type 4) to help the wind turbine work more collaboratively with the grid in high-VRE-contribution scenarios.

Table 3. Wind Turbine Type and Control Capabilities

\begin{tabular}{|c|c|c|}
\hline Wind Turbine & Generator & Grid Forming | Inertia | Voltage Support \\
\hline Type 1 & $\begin{array}{l}\text { Asynchronous generator (by grid } \\
\text { frequency) }\end{array}$ & No (need external support) \\
\hline Type 2 & $\begin{array}{l}\text { Asynchronous generator/wound-rotor } \\
\text { induction generator ( } 10 \% \text { variable } \\
\text { speed) }\end{array}$ & $\begin{array}{l}\text { Possible (limited control, frequency- } \\
\text { dependent, rotor resistance control, with } \\
\text { possibility of increased losses) }\end{array}$ \\
\hline Type 3 & DFIG ( $30 \%$ power converter) & $\begin{array}{l}\text { Possible (more flexible compared to Type } 2 \\
\text { as a result of power electronics) }\end{array}$ \\
\hline Type 4 & $\begin{array}{l}\text { Synchronous } \\
\text { generator/asynchronous generator: } \\
100 \% \text { power converter }\end{array}$ & $\begin{array}{l}\text { Highly flexible as a result of larger power } \\
\text { electronics, completely decoupled from grid, } \\
\text { synthetic inertia (fast frequency response), } \\
\text { expensive }\end{array}$ \\
\hline
\end{tabular}


Earlier generations of fixed-speed wind turbines used static synchronous compensators and/or capacitor banks to ensure the high-quality power that the grid codes demand from wind generation. Type 4 wind turbines are decoupled from the grid via their power electronics during their normal operation. This isolation from the grid can either be an advantage or disadvantage to the wind turbine. As a major player among VRE, a wind turbine must share its responsibility of being a part of the integrated power system, which will further open up the possibilities of higher penetrations of VRE into the power system. Innovations in power electronics and control functions can make this possible. However, much needs to be done for distributed wind to develop required flexible functionalities to meet requirements of grid codes and standards and provide grid support functions for reliable and resilient operations.

\subsection{Active and Reactive Power Support}

Active power control and reactive power control aims to adjust a wind turbine or wind farm's active and reactive power at multiple time scales. Wind resources are variable in nature and will have an uncertain forecast. Moreover, the wind turbine's frequency is not typically synchronized to the frequency of the power grid and is generally unresponsive to changes in system frequency. These three characteristics of wind energy-based generators - variability, uncertainty, and asynchronism - are challenges for maintaining power system reliability. With larger geographic regions covering more balancing areas, the aggregate variability and uncertainty can be reduced. Some independent system operators have also considered controlling the active power (curtailment) from large utility-scale wind farms to provide downregulation services in the market (under the name "dispatchable intermittent resources"). Therefore, wind power plants, which are typically non-dispatchable, are beginning to be dispatched via innovative controls and integration practices. A number of factors influence the control strategy, including wind resource availability, ability to forecast accurately, and synergistic resources available in the grid such as storage (Madjidian 2016) at local or regional scales. Direct control of active power of wind turbines is also one of the options, further described in Section 3.4.1.

\subsubsection{Active Power Control}

Figure 5 summarizes the ways to realize power control, beginning with (1) active power control (APC): setting an upper maximum limit and curtailing any wind power above that dispatch level; (2) gradient power control: controlling the ramp rate of wind power out to limit the ramping and thereby mitigate netload ramps and the associated reserves needed; (3) delta power control: reserving a constant headroom MW "delta" by pre-curtailing from the available power, so that wind plant can also provide reserves (i.e., spinning reserves, contingency reserves, ramping up); and (4) frequency power control (addressed in Section 3.5), in which one of the aforementioned controls could be implemented to maintain grid frequency within allowed upper/lower limits. Beyond a frequency dead band, APC will keep the frequency within limits, preventing generator tripping or load shedding protections. Some past relevant publications include Nock, Krishnan, and McCalley (2014); Howland et al. (2014); and Fang et al. (2018). 

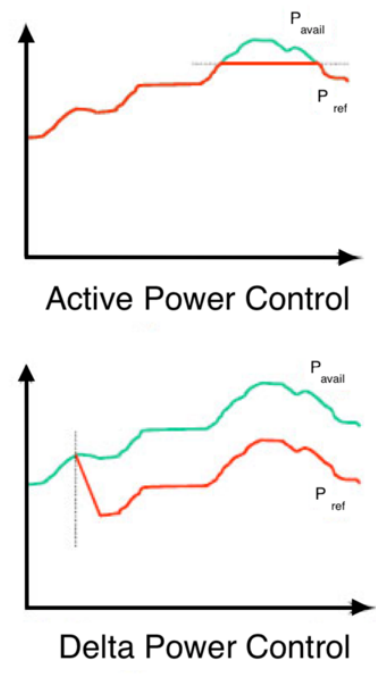
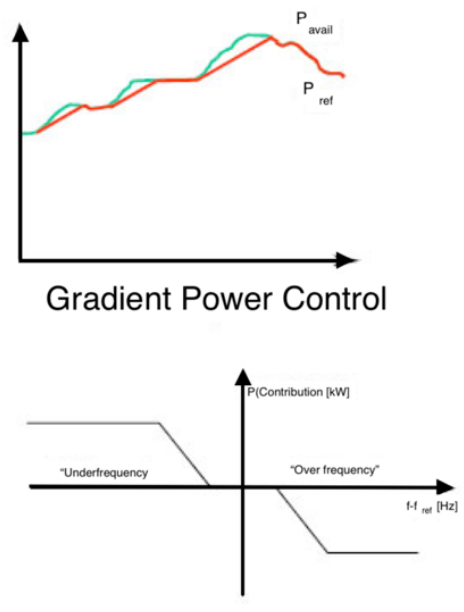

Frequency Control

Figure 5. Active power control functions (UVIG IEEE 2009)

A team from NREL, University of Colorado, and Electric Power Research Institute (Ela et al. 2014) looked at three of the forms of APC. A focus of the study was synthetic inertial control, primary frequency control, and AGC regulation. A conclusion of the study, based on wind turbine simulations and field tests, is that wind turbines can provide a satisfactory response for primary frequency control and AGC. Power system dynamic studies show that wind can generally improve reliability when providing primary frequency control and synthetic inertial control. In addition to systematic management of available power through APC, two other studies (Lori, Jaquelin, and Xi 2014; Ryan and Mark 2019) also summarize examples of wind energy curtailment practices internationally and in regions across the United States.

\subsubsection{Derated Operation}

A wind turbine can be made to operate at a power level below the available power. Refer to Figure 5 for various ways of performing active power control, namely curtailing beyond an upper limit, limiting the rate rates, performing delta control, or responding to frequency events. The derating may be done for several reasons, including situations such as (but not limited to):

- Responding to a large wind power ramp

- Alleviating transmission congestion

- During minimum loading times (e.g., night), with several conventional generators at their minimum allowable generation levels (i.e., situations when the grid doesn't have any more flexibility to accommodate more wind energy)

- Alleviating any local wind turbine operational safety concerns (e.g., as indicated by temperature or vibrational sensors)

- Providing ancillary or essential reliability services such as regulation or spinning reserves or ramping product (especially in the upward direction).

The derating is achieved by simply curtailing the wind power below a certain maximum value, or particularly through "delta control," in which the derating is performed normally by modifying the power set point (say, a constant "delta") and subsequently adjusting the turbine control input, 
namely generator torque and blade pitch corresponding to the commanded power. At times, derating can also be performed proportional to the available wind, say by some $x \%$ called "proportional control" (instead of constant delta all the time) (Ela et al. 2014). Obviously, the derating takes place at suboptimal level on the physical surface of the wind turbine. In addition, wind turbine derating can be accomplished by modifying the rotor speed set point (Lio, Mirzaei, and Larsen 2018). Two levels of power output set points are common in industry to operate the wind turbine at low and near-rated wind speeds.

\subsubsection{Reactive Power Support}

The amount of reactive power support available to provide VARs to a system is related to the amount of power available from the wind resource. Therefore, variable resources sometimes use auxiliary VAR devices to provide reactive power, in addition to their power electronics controls.

Type 1 and Type 2 wind turbines use variable capacitor banks to regulate reactive power at the turbine level such that the overall wind farm power factor is close to unity. Wind turbine generator Type 3 and Type 4 have the ability to control the reactive power and real power instantaneously and independently via their power converters (Singh, Muljadi, and Gevorgian 2012). Modern wind turbines that employ power electronics are continuous sources or sinks of reactive power. Conventional wind turbines use external components like capacitor banks, static synchronous compensators, or static VAR compensators to regulate the reactive power for the wind turbine (Zhang et al. 2017). The transformer connecting the wind farm to the grid can also use load tap changers to regulate the reactive power output. A variable-speed wind turbine that utilizes a DFIG is considered a limited source of reactive power.

IEEE standard 1547-2018 stipulates minimum reactive power injection and absorption capabilities of distributed energy resources. The recommendations (IEEE 2018) are applicable for active power output levels greater than or equal to the minimum steady-state active power capability, or $5 \%$ of rated active power of the DER, whichever is greater.

\subsection{Frequency Support}

If the frequency of a power system reduces below a certain value, connected generator protection devices and under-frequency load shedding (UFLS) relays will be activated to trip or shed loads, helping to prevent a brownout or a blackout event. In conventional grids, synchronous generators provide the necessary inertia as well as other controls (primary response through governor and secondary response through AGC regulation) to support a desirable frequency response in which the nadir is not too low to trip UFLS relays, nor is the ROCOF too fast to trip protective relays. However, in a grid with higher inverter interfaced DERs that replace conventional synchronous generators, system inertia is reduced, therefore leading to a steeper ROCOF and higher risks of UFLS relays tripping (shedding loads).

\subsubsection{Frequency Support from Solar PV Research}

Figure 6 shows the control of smart inverters (Hz-watt or frequency-watt) (Hoke et al. 2017) to detect ROCOF and release real power using a droop control. The result indicates recovery of grid 
frequency in a timely manner to obviate the UFLS tripping, as shown in the right-hand side of the figure.

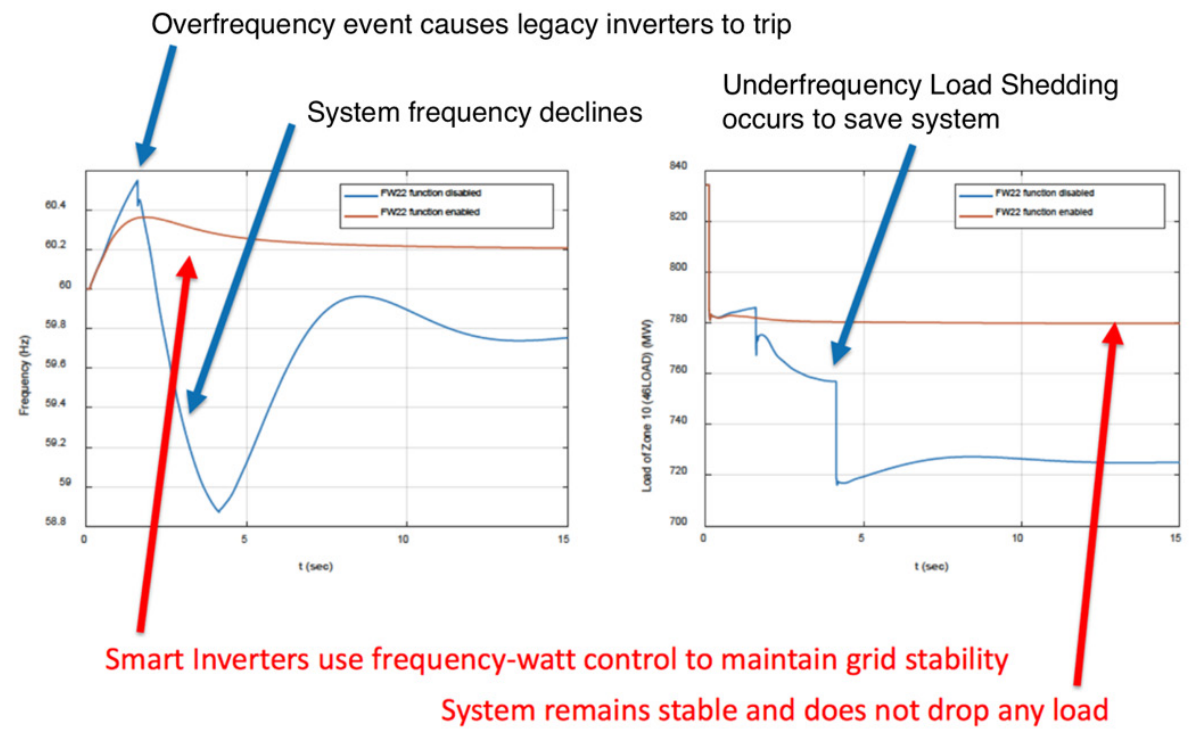

Figure 6. Hz-watt control of smart inverter (solar PV) to provide frequency response

\subsubsection{Frequency Support from Wind Research}

A wind turbine employing advanced controls can provide frequency support to the grid it is connected to, using its mechanical inertia and power electronics, whether a bulk power or isolated microgrid system. A frequency support function of a DER requires the generator to respond to the frequency as a demand and generation function at the given instant. A wind turbine, utilizing an advanced controller, can leverage kinetic energy stored in the rotating parts of the wind turbine to respond to the grid frequency signal. Accordingly, a wind turbine can provide an inertial response as well as the primary frequency control function. These functions generally come at the cost of the total energy production, which is normally optimized through the Maximum Power Point operation of the wind turbine.

IEEE 1547 provides an example frequency-droop curve for a DER connected to the power system. Figure 7 from IEEE 1547-2018 presents droop curves for three different loadings of DER and regions where DER is expected to isolate its contribution (IEEE 2018). 


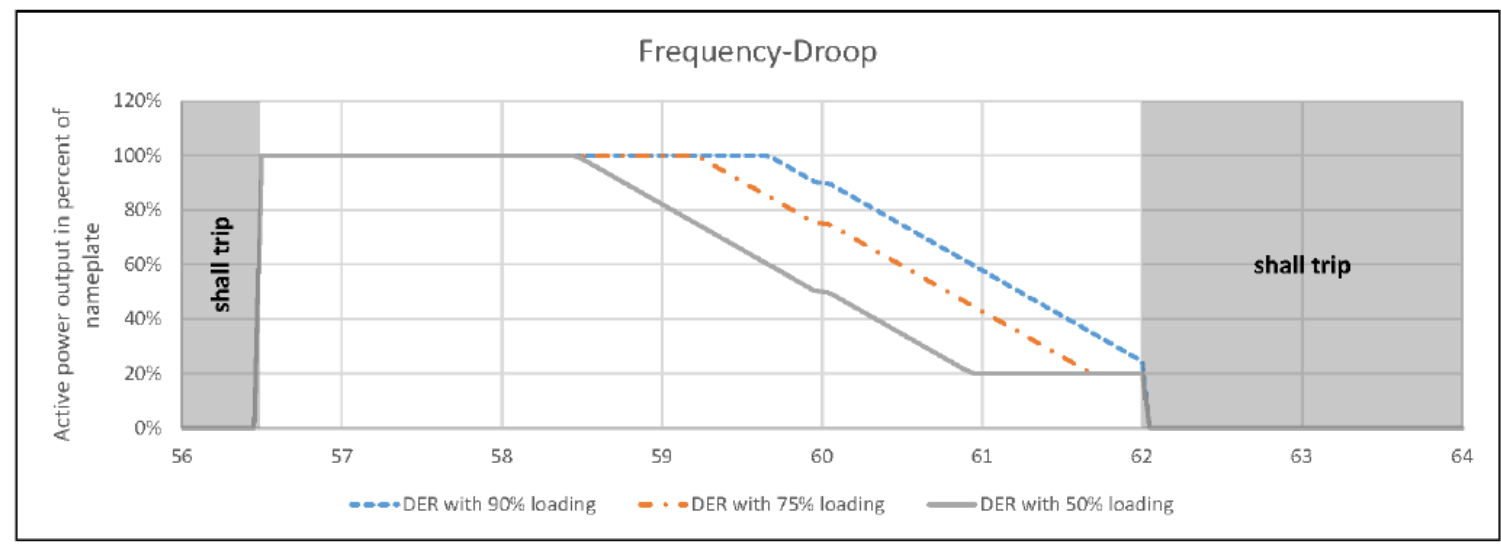

\section{Example of a three frequency-droop function curves with a $5 \%$ droop, $36 \mathrm{mHz}$ deadband, and $20 \%$ minimum active power output for DER operating at different pre-disturbance levels of nameplate rating $(50 \%, 75 \%$, and $90 \%)$}

NOTE-A DER response during low-frequency conditions may be subject to available active power and the predisturbance dispatch level.

Figure 7. Example frequency-droop function curves (IEEE 2018)

The frequency support from a wind turbine can also be in the form of APC, as mentioned in Section 3.4.1 (Ela et al. 2014). The basic ideas include rotor inertial control and synthetic inertia (Tamrakar et al. 2017). Advanced controls can make a wind turbine or farm grid-friendly. GE has demonstrated some advanced controls at the transmission level (Miller 2013), and this has been adopted by a number of utilities and balancing areas; this can also be utilized for distributed wind controls. A team at NREL looked at the frequency-watt function, which is optimal for the Hawaiian electric companies utilizing both simulation and field testing (Hoke et al. 2017). The study demonstrated the activation of frequency-watt control in distributed PV inverters, which resulted in an increase in grid stability. A Ph.D. thesis at Ghent University (Vyver 2016) examined the issue in more detail, including an additional control loop for the Type 4 wind turbines to generate a response to the various states of the grid.

\subsubsection{Inertial Support for a Grid with $100 \%$ Inverter-Based Resources}

For a grid with 100\% inverter-based resources (IBRs), synchronized operation and power sharing among all becomes a challenge. Traditionally, IBRs are operated in a grid-following mode, meaning an external power or voltage signal is sent to their outer control loop, and the inverter follows that signal. Commercial inverters are commonly configured to operate as current source inverters in distribution applications, meaning they provide current to supply the load connected in parallel. Typically, in traditional grids, synchronous generators set the frequency $(60 \mathrm{~Hz})$ and voltage set points, which ensure real/reactive power-sharing coordination among all resources. For example, to maintain an acceptable frequency response, the AGC module estimates the area control error and each generator shares real power based on its droop characteristics (i.e., change in real power for a unit change in frequency, $\Delta \mathrm{P} / \Delta \mathrm{f}$ ) (NERC 2019). 
In an isolated grid with 100\% IBRs, without synchronous generators setting the frequency, inverters can operate in a "grid-forming mode" and can be adjusted to also set a constant supply frequency and voltage. In this situation, one or a few IBRs can act as grid-forming inverters, and the rest can share power based on their droop control characteristics. Given that some DERs may have power production limitation, studies have also proposed adaptive droop techniques in which the power-sharing proportion among DERs are varied with respect to current DER status and forecasts (Bidram and Davoudi 2012). The previous droop control technique is in the frequency domain and is slower than a time domain control that a typical IBR could do as a result of its very fast time constants. Therefore, Johnson et al. (2016) developed another technique for IBR coordination in the time domain for instantaneous control and coordination, which also ensures better synchronization among all IBRs, convergence, and stability. This is based on the principle of oscillators (Van der Pol oscillator) that can generate and self-sustain an oscillation signal of particular magnitude and frequency using the feedback from the plant (typically error signals). They call this virtual oscillator control (Johnson et al. 2016), as the oscillator in this case was coded in a microprocessor, as shown in Figure 8. Instead of depending on an external signal for the outer loop, a self-sustaining signal comes from the virtual oscillator control microprocessor and the inverter is controlled to maintain the commanded voltage and current. Load sharing is implemented across multiple such virtual-oscillator-control-enabled voltage source converter inverters ( $\mathrm{Lu}$ et al. 2019). The stability characteristics of such control algorithms are still being investigated.
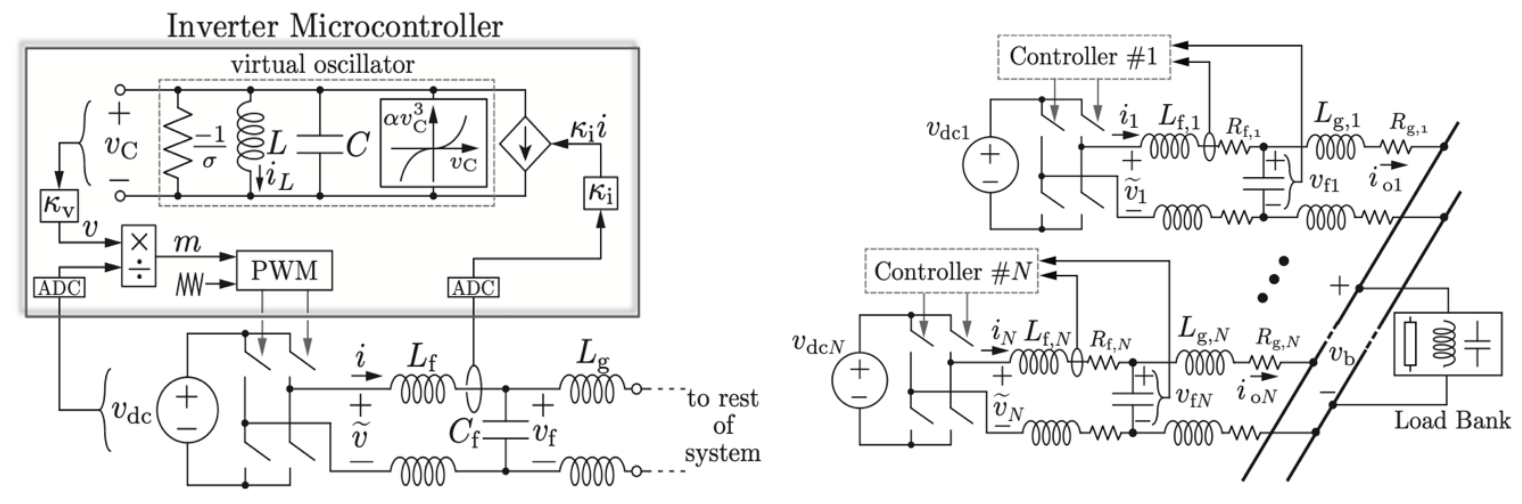

Figure 8. Virtual oscillator control for multiple IBRs (Lu et al. 2019)

\subsection{Voltage Support}

Previously, DER interconnections were seen as passive grid-following resources that typically tripped at slight grid disturbances for safety reasons. Now, DER interconnections have evolved to providing active grid-supporting functionalities that include fault-ride-through capabilities as well as active voltage and frequency support through real and reactive power controls. Much of this evolution has been facilitated by research studies in collaboration with industries that informed the evolving IEEE 1547 standards on DER interconnection (Palmintier 2019), as shown in Figure 9. 


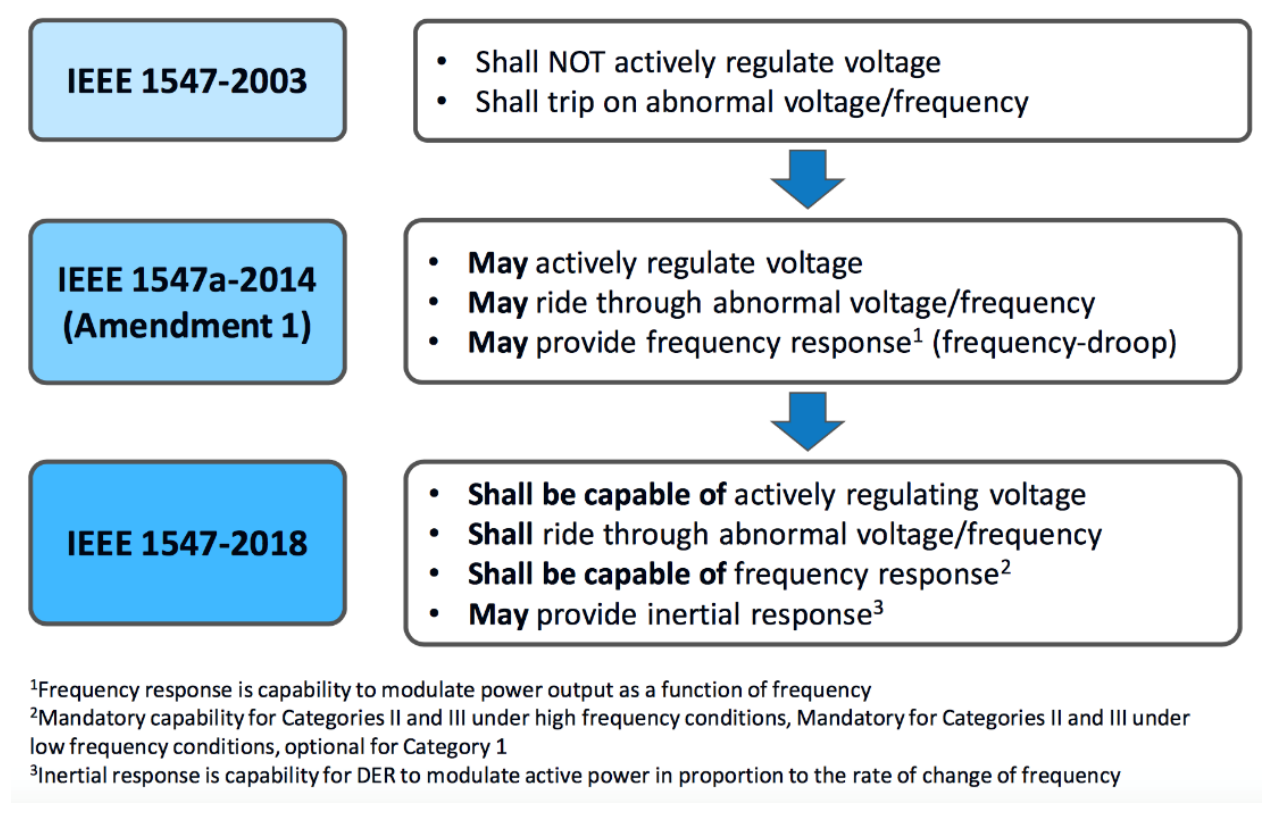

Figure 9. IEEE 1547 evolution informed by DER interconnection and smart inverter studies (Palmintier 2019)

\subsubsection{Solar PV Inverter Control - Power Factor, Volt/Var and Volt/Watt control}

Several studies in the domain of advanced smart inverter controls for solar PV were done by NREL in collaboration with Hawaiian Electric Company (HECO) to address several of their pressing issues related to efficient interconnection of distributed solar PV and the smart controls of inverters. At some point, HECO had a moratorium on interconnection of PV systems because of undesirable voltage impacts on their feeders. Now, with advanced control of smart inverters, Hawaii is on the path to realize their goal of $100 \%$ renewable energy by 2045, a major portion of which is supported by the interconnection of thousands of distributed solar PV on their distribution feeders.

Originally, HECO had set all of their inverters at unity power factor to maximize the real power output from the distributed PV, which resulted in some feeders experiencing very high voltages during daytime when solar power output was high (belly of the duck curve). Then, inverter controls were utilized to set the inverters at a $95 \%$ power factor, which let the inverters absorb reactive power from the grid, thereby reducing the voltage impacts during the peak solar output periods. This functionality came with the cost of losing the real power yield at all times (curtailed real power), as the inverters were set constantly at 0.95 power factor and some of the inverter's capacity was used for reactive power production.

After a series of projects with HECO, NREL then developed simulation studies to quantify the benefit of volt-VAR and volt-watt functionalities of smart inverters to ascertain their benefits for voltage regulation as well as reduction in real power curtailment. Figure 10 shows HECO's Rule $14 \mathrm{H}$, which defines the volt-VAR (top plot) and volt-watt (bottom plot) functionalities. The voltVAR plot indicates the production or absorption of reactive power by inverters (through dualloop vector control) for point of common coupling voltages below 0.97 per unit or above 1.03 
per unit, respectively, in a linear fashion up until the ANSI limits of 0.94 per unit (1.06 per unit). Then, for very severe voltage raise (beyond 1.06 per unit), which is not able to be brought down within the ANSI limit of $<1.05$ per unit through volt-VAR control, volt-watt control functionality is activated, which curtails the real power production by the PV panels.
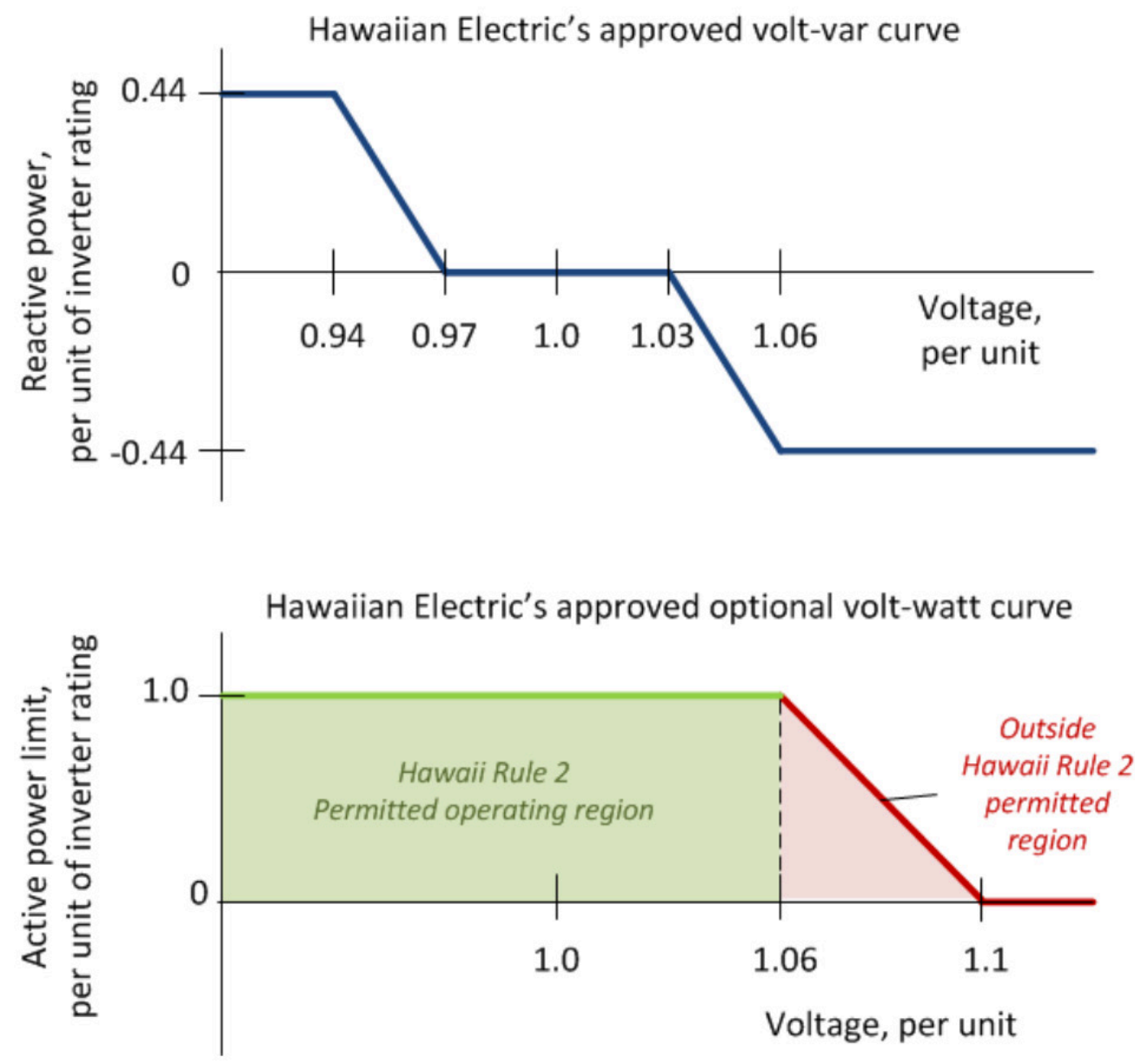

Figure 10. HECO Rule 14H volt-var (top) and volt-watt (bottom) functionalities of smart inverters

NREL modeled a few selected HECO feeders with distributed PV resources and simulated their quasi-steady-state responses using OpenDSS software (using python or MATLAB's Component Object Model [COM] interface) (Giraldez et al. 2017). One of the feeders (named Mikilua 34) with three PV systems was simulated under two scenarios: (1) legacy PV systems and (2) PV systems with smart inverters (volt-VAR control). Figure 11 shows the impact of volt-VAR control ( $\mathrm{x}$-axis shows feeder distance in miles, and $\mathrm{y}$-axis shows voltage per unit), where we observe that the secondary-line voltages have been brought within the ANSI limit of 1.05 per unit by the volt-VAR control, compared to a legacy PV that was at unity power factor. The study also verified that the real power curtailment resulting from the use of volt-VAR control functionality was minimal in the feeders $(<2 \%)$; however, the voltage regulation gain was appreciable. 
After the simulation study, NREL also performed pilot field testing at HECO feeders and collected real-time data from their grid sensors (GRID20/20 distribution transformer meters and AMI data) (Giraldez et al. 2018). The plots in Figure 12 summarize the results and confirms the observation from the aforementioned simulation studies. In the month of June 2019, volt-VAR inverter control helped regulate steady-state voltages within ANSI limits.

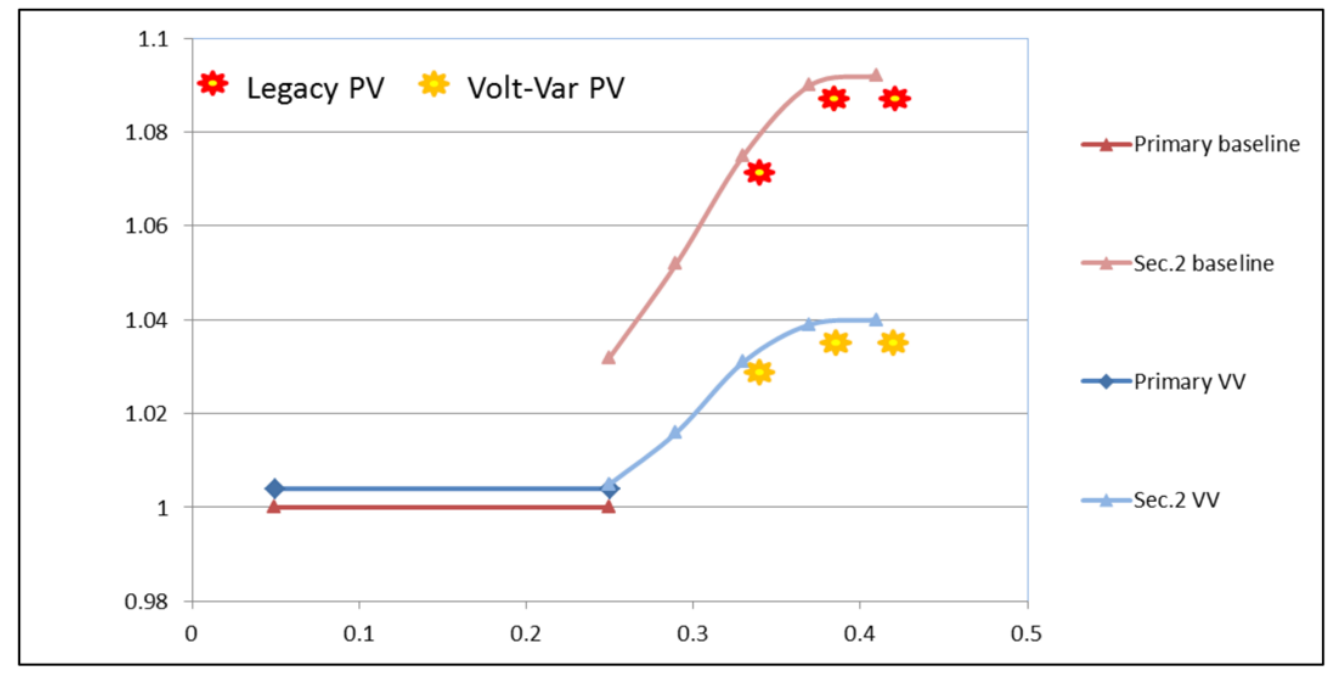

Figure 11. Mikilua feeder results summary: volt-VAR control functionality improved voltage profile (Giraldez et al. 2017) 

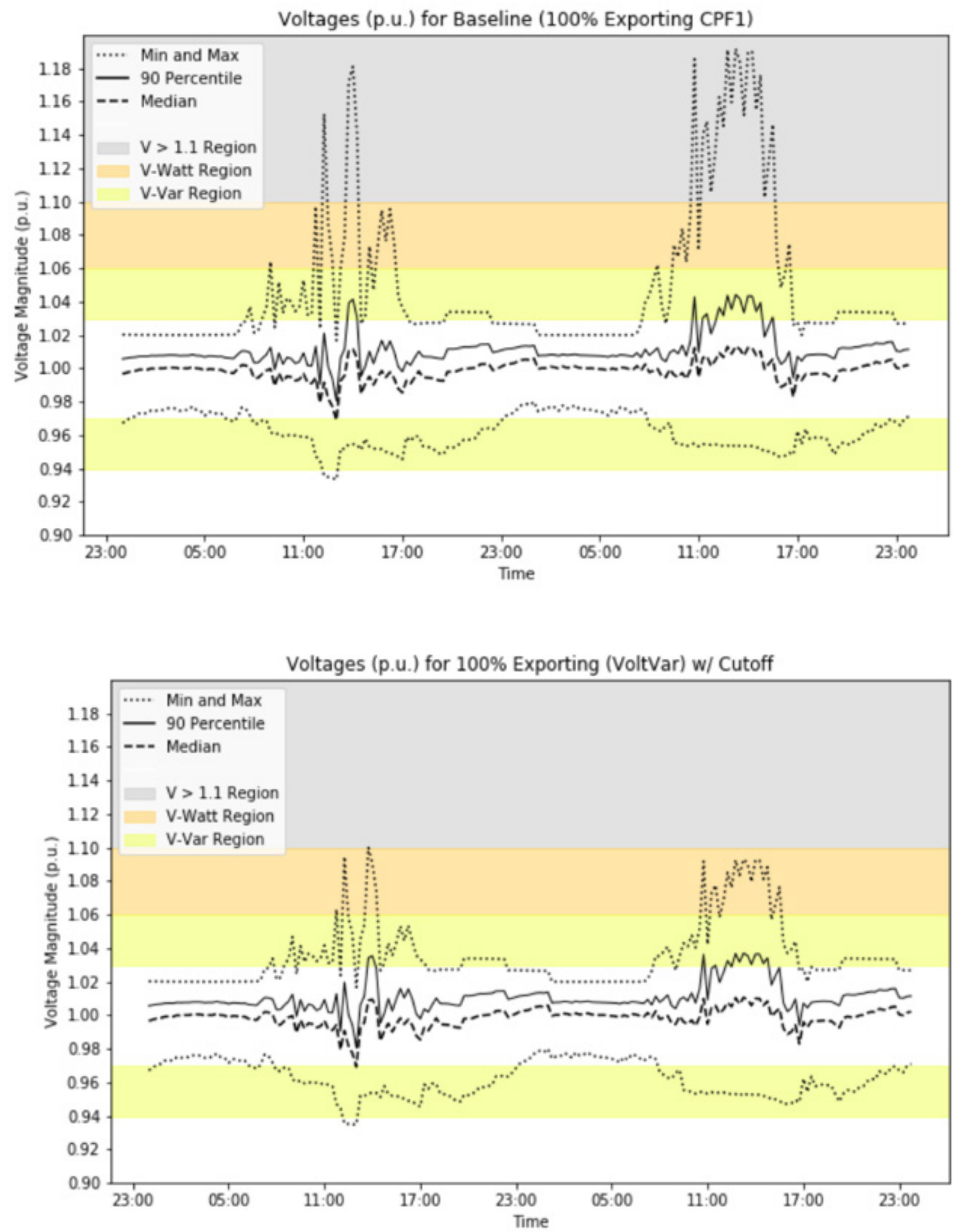

Figure 12. Mikilua voltages: (top) unity power factor; (bottom) volt-VAR

\subsubsection{Wind Voltage Control}

The controls mentioned in Figure 9 (constant power factor, volt-VAR and volt-watt) are possible to be performed in Type 4 wind turbines interfaced with full converters (much like solar PV). Additionally, the Type 3 (DFIG)-based wind turbine can have reactive power capability, subject to its power electronic rating. Figure 13 (Gevorgian et al. 2019) shows the reactive capability 
from different devices, including conventional synchronous generators (whose capability is subject to minimum power level, thermal rating, and stability limits), PV inverter, Type 4 wind turbine, Type 3 wind turbine generators, and BESS (which can provide reactive support during both charging and discharging operations).

A recent NREL study (Gevorgian et al. 2019) demonstrates the reactive power control capability of a GE 1.5 wind turbine. At the NREL Flatirons Campus, researchers routinely use the GE 1.5 wind turbine to bring the voltage across the site to levels needed by other equipment for experiments. The study also performed PHIL testing using the controllable grid interface and RTDS interface (communicating signals at $40-\mathrm{kHz}$ frequency) to demonstrate various types of active and reactive power control by wind generation, including inertial response, primary frequency response, wind participation in AGC, reactive power and voltage control, and faultride-through performance.

Additionally, there have been many other studies demonstrating wind turbines' voltage support capabilities, including recent demonstration studies by the California Independent System Operator (California ISO 2020b) and Avangrid (California ISO 2020b). The results show that a commercial wind plant with an inverter-based smart controller can provide services such as balancing or up- and down-regulation of power, voltage, and frequency.
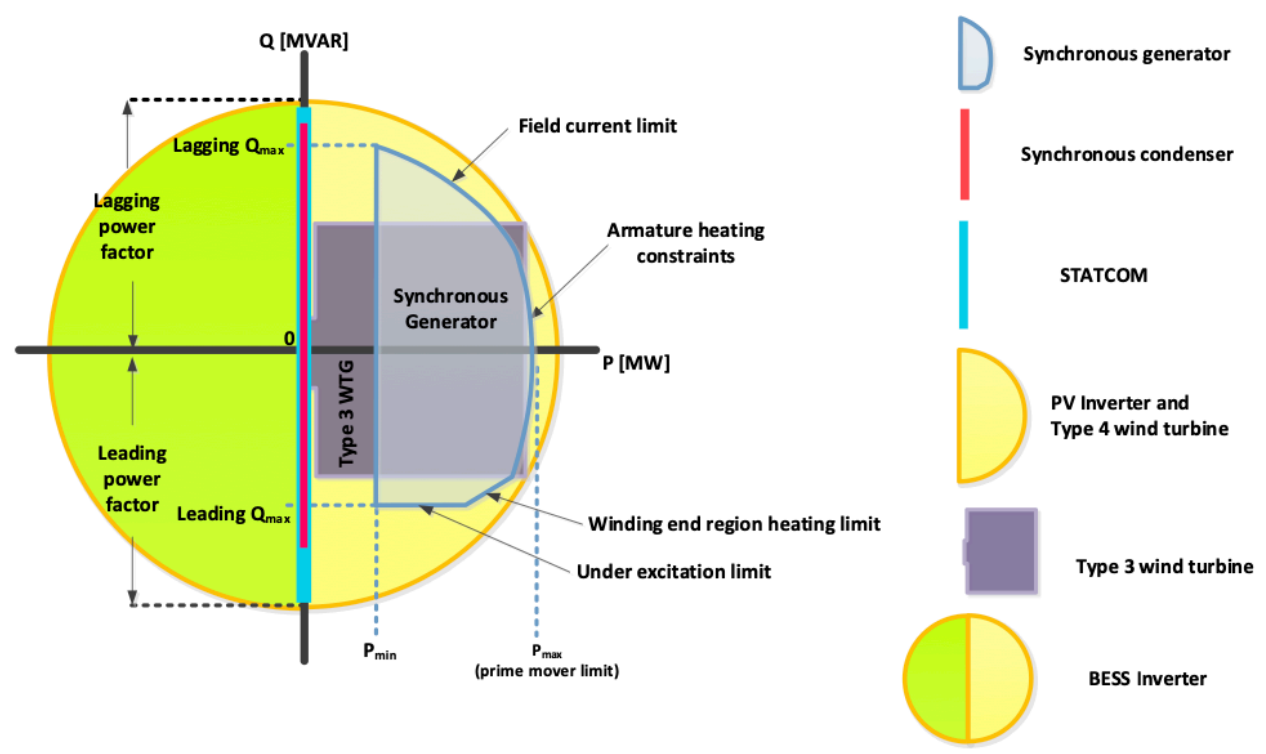

Figure 13. Reactive power provision for voltage control from different sources (Gevorgian et al. 2019)

\subsection{Power System Restoration Using Variable Renewable Resources}

Power system restoration is a process of energizing the grid after a complete blackout resulting in a major customer outage. There are well-established procedures (Adibi et al. 1987), summarized in Figure 14. This section covers past research and future needs where variable renewables, particularly distributed wind controls, can play a role in the restoration process by 
(1) providing black start and (2) minimizing the restoration time while maximizing load pickup. In all of these applications, improvement in load and variable renewable forecasts is a muchneeded component (as shown in the first box of Figure 14), especially at high spatial and temporal resolutions at near-real-time resolutions. The state of the art for real-time forecasts at 5-15-min intervals are based on persistence or statically enhanced smart persistence, and future improvements look to integrate high-resolution data from geostationary (GOES-R) satellites (economical for larger spatial resolution) and sky imagers (high temporal resolution for a local region).

Further discussion in this section will focus on the control capabilities and research needs for enabling distributed wind to aid the system restoration process.
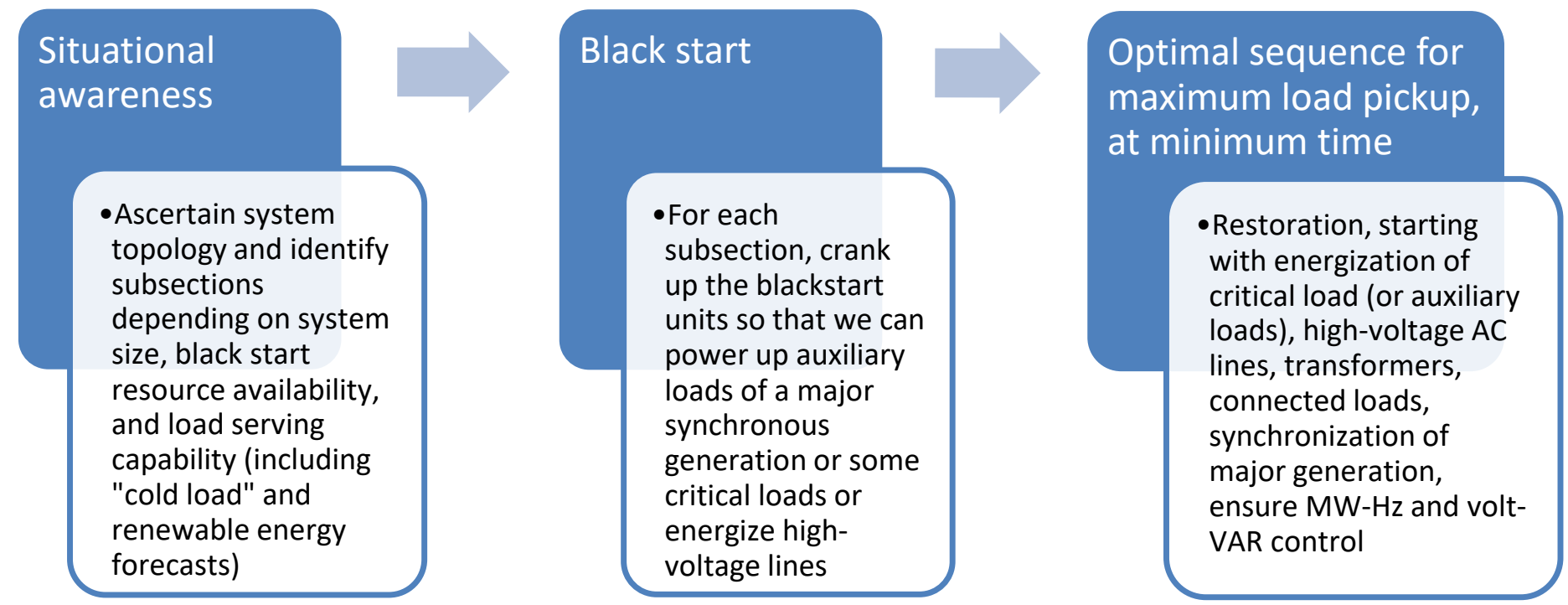

Figure 14. Restoration process overview, with black start (Adibi et al. 1987)

\subsubsection{Black Start}

Black start is the first step in the restoration process, aside from situation awareness and an understanding that the system is safe to begin restarting. When a grid is down without any energized lines to carry power, a generation system needs to self-start and help the rest of the grid come back to power and supply all loads. There are certain facilities that operate as black start units, capable of self-starting alone or with the help of a local diesel generation set or battery bank to power their auxiliary loads, so that they can function autonomously. Performing a black start using inverter-connected sources has been a major topic of interest for utilities and system operators that are seeing increasing levels of inverter-based sources, including variable renewables. California demonstrated using battery energy storage to perform a black start (Colthorpe 2017) by helping to start some auxiliary loads in a major power station. A potential area of future research is variable renewables supporting black start, likely when coupled with battery storage. 
Studies have also shown that voltage-source, converter-based, high-voltage DC lines can be excellent black start resources (Jiang-Hafner et al. 2008). Given the size of the typical voltagesource-converter-based high-voltage DC (typically $300 \mathrm{MW}$ or so), whose topology is shown in Figure 15, the converter provides a large range of real and reactive power control to ensure frequency and voltage stability during the process of sequential load pickup, equipment energization, and restoration. Jiang-Hafner et al. (2008) demonstrated its capability to energize a large transformer, induction motor load, and AC line that connects to loads and help synchronize a large synchronous generator that can further help in load pickup and restoration.

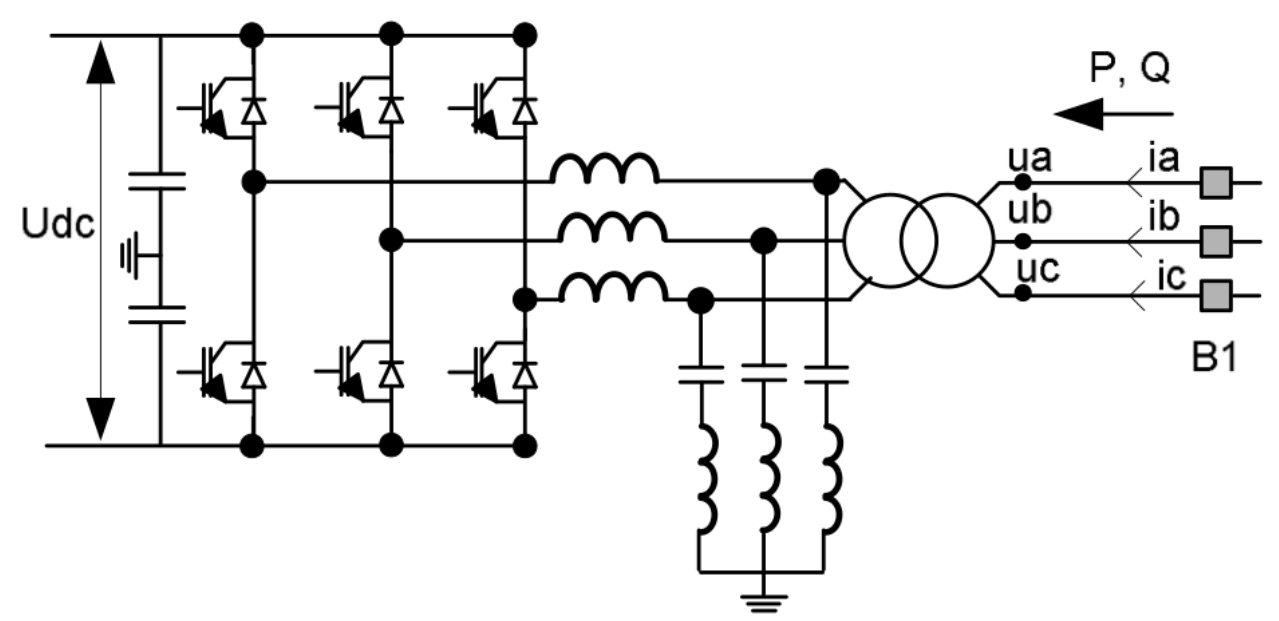

Figure 15. Voltage-source converter high-voltage DC topology, an excellent black start resource Although inverters provide black start in the high-voltage DC example shown in Figure 15, they are larger than a typical inverter that interconnects a PV or wind resource. Unlike internal combustion engines, inverters are current-limited and are only capable of picking up a slightly higher current than their normal current rating. In a recent study, NREL simulated the capability of an IBR inverter providing black start capability to inductive loads (Jain et al. 2020). This paper focuses on the modeling and simulations required to black start inductive loads because (1) these loads are encountered during a black start of critical loads, such as natural gas compressors and auxiliary equipment of the next-start power plant and (2) they can result in large transient inrush currents (typically six to eight times the rated current), which the typical inverters used in similarly rated IBRs are unlikely to be able to provide.

To evaluate the technical feasibility of IBR inverters providing black start, a behavioral model of inverters that mimics current-limited inverter operation was developed using variable resistors in the MATLAB Simulink/Simscape environment. The inverter model, with a current limit of 1.2 times the current rating, is connected to an induction motor through transformers and a transmission line to simulate its startup. Simulation results show that even with the limited current supply capability of inverters because of their physical constraints, IBRs can black start a motor under certain conditions. Results also show that by using soft-start techniques, such as ramped supply voltage, and connecting transformers in series with the loads, inrush currents can be reduced, thereby expanding the conditions under which IBRs can provide black start support. 
Similar issues exist when energizing a transformer, which requires inrush current. Research has shown alternative configurations, with smaller interim start-up transformers to alleviate the issue (Kahrobaee, Algrain, and Asgarpoor 2013).

\subsubsection{Black Start from Wind Plant}

The capability of wind black start is heavily dependent on the amount of power available through the wind resource. Most methodologies for valuing wind as a black start resource would be heavily risk-based, with the knowledge that the wind may not be available when the black start service is required. With improved forecasting, the risk associated with variability of wind resource would be reduced.

For a wind turbine to be able to self-start, some form of auxiliary power supply would be required during startup (National Grid ESO 2019). New and existing wind farms will not automatically have a sufficiently sized auxiliary power supply for black start purposes, but retrofitting such equipment is technically possible. A diesel generator or an electrical energy storage system has the potential to provide the power to start a wind turbine. It has been observed that some large international offshore wind farms tend to use diesel generators on the platform (or in the turbines) to provide the initial energy requirements of the wind farm.

After self-start, to further energize other components in the grid such as induction motors, transformers, and $\mathrm{AC}$ lines, the turbine must provide the needed voltage support (inrush current during the start). It was shown previously that Type 3 DFIG-based wind plants have the ability to support large short-circuit currents, and thereby also large inrush current (Muljadi et al. 2010). For Type 4 full-power converter-based wind power plants, where the maximum current capability is limited to the inverter size, challenges exist in terms of their current capability. Therefore, in such plants, the inverters may need to be oversized. In any case, it is technically feasible for a wind plant to provide black start, and the question is about the economics and improved forecasting, or a co-located battery resource in place in a hybrid setting to ensure the availability of service (Gevorgian, Shah, and Koralewicz 2019 ). Research is needed to quantify these value streams and cost-benefits for stand-alone distributed wind systems and wind-storage hybrids. These efforts will be evaluated under the MIRACL project and other future distributed wind research efforts.

\subsubsection{Energization Sequence: System Restoration}

Restoration requires a sequence of energization of loads and equipment to gradually power up the entire grid, including reconnecting multiple smaller islands and synchronizing. The objective is to minimize restoration time and maximize load pickup. During such operations, reactive power support is needed to absorb or consume the reactive power (e.g., an unloaded AC line will be a reactive power producer, and hence we need the already online units to absorb it, whereas a transformer or motor load will be a reactive power absorber, and hence we need the online units to produce reactive power). For both real power and reactive power control to support the grid frequency and voltage during various stages of restoration, wind power plants or inverter interconnected plants can play a role to support the system. This ensures faster system recovery and higher load pickup capability. During these times, the variable renewable resources 
themselves may cause frequency and voltage fluctuations because of their variability and uncertainty, but the control research developed in MIRACL and other projects can help ensure variable renewables are indeed helping the grid during restoration. Figure 16 shows one example of such real power control, where a variable renewable generator is dispatched below the available power (forecasts) by some "constant delta," and this delta is used to provide ramp up/down service to support the grid frequency (Braun et al. 2018).

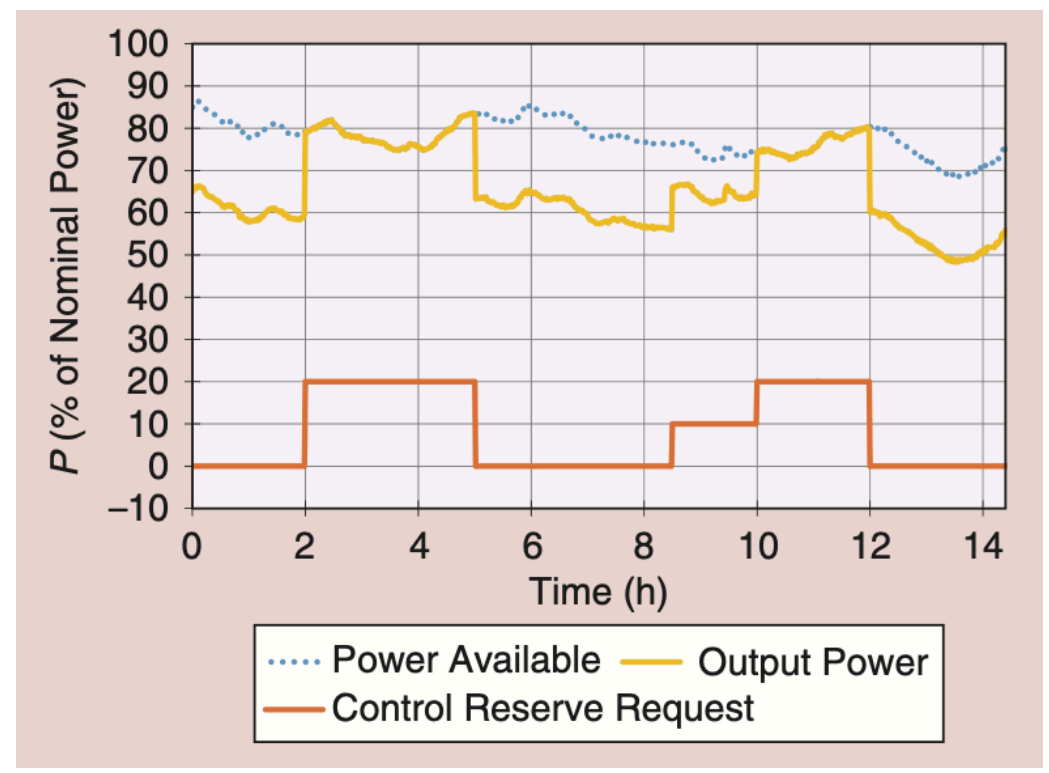

Figure 16. Variable renewable "delta" mode for active power control for frequency support during restoration 


\section{Wind-Battery Integration Research}

Batteries can help integrate VRE into power systems. In a microgrid, a dispatchable system like a battery, which can function both as a sink as well as a source, has an even bigger role to play to enhance the value of VRE, system stability, and resilience. MIRACL battery integration research focuses mainly on engineering and economic aspects of the technology. Lithium-ion chemistry is the most widely used technology given its superior energy density and cost per unit throughput. Our focus will be on performance characterization of lithium-ion batteries and added economic value associated with the integration of batteries with existing power electronics of distributed wind.

As part of the MIRACL effort, battery integration research has focused on lithium-ion battery modeling and analysis, as follows:

- Integrate a generic battery model with a wind turbine model for dynamics simulation in MATLAB/Simulink environment and similarly for a lithium-ion battery.

- Size a battery for integration at the DC link of wind turbine's power converter (Type 3 and Type 4) to improve fast frequency response in a microgrid use case. This research will also develop a guideline for sizing battery at various distributed wind contribution levels.

- Integrate battery storage in DC and AC systems through DC/AC coupling behind the point of common coupling and validate with field data.

In summary, utilizing a validated dynamic model of a battery, we plan to study the following aspects, outlined in Sections 4.1 and 4.2, associated with the MIRACL use cases.

\subsection{Wind-Battery Hybrid Grid Services}

Along with an advanced and predictive control of wind turbine systems, the MIRACL project plans to study a wind turbine with battery storage integrated in the DC link that can support the dispatchability of the system. Our focus is to quantify additional capabilities enabled by advanced control functions under the various MIRACL use cases outlined in Section 1.1. The wind turbine, with integrated energy storage, can provide inertial support to improve stability of the grid. NREL will simulate the distributed wind and battery in a dynamic environment and plans to validate simulation through a field-testing capability to be built as part of this MIRACL project.

In 2019, a team at NREL evaluated how grid-scale energy storage can support power system flexibility and high-level contributions of renewables to the U.S. electric grid (Bowen, Chernyakhovskiy, and Denholm 2019). This study outlines the following grid services possible from using BESS, which can be reproduced for wind-storage hybrids to show specific benefits across the four MIRACL use cases:

- Arbitrage: load leveling

- Firm capacity or peaking capacity

- Operating reserves and ancillary services

- Transmission and distribution upgrade deferrals 
- Black start.

Additionally, studies have shown BESS to support frequency response and gain from "pay for performance" from co-optimized energy and ancillary service markets (Krishnan, Das, and McCalley 2014). The challenge will be to efficiently forecast the variable renewable, including distributed wind, and appropriately dispatch the BESS to ensure improved system economics and stability (Das, Krishnan, and McCalley 2015). These will also be investigated for wind systems with integrated battery storage, as the challenges and benefits will vary for these specific systems.

As shown in Figure 17, BESS can be connected in different ways using inverters (Denholm 2017):

a) AC-coupled connection where both BESS and renewable source are connected via their own DC-AC inverters (typically more suited for a large-scale battery interconnection with direct connection to the grid)

b) DC-coupled connection where the BESS is connected via a bidirectional DC-DC rectifier for better output control, and then interconnected to the renewable source at the DC link. This figure shows a PV plant; however, for a wind plant, the connection can happen at the DC link of the Type IV turbine.

c) Configuration where the BESS (without a separate DC-DC rectifier) is directly connected at the DC link of the renewable source connection, and both are considered as a hybrid source, connected to the main grid via a DC-AC inverter.

Each of these hybrid connections have their pros and cons in terms of the services they are able to provide and the cost of the design.

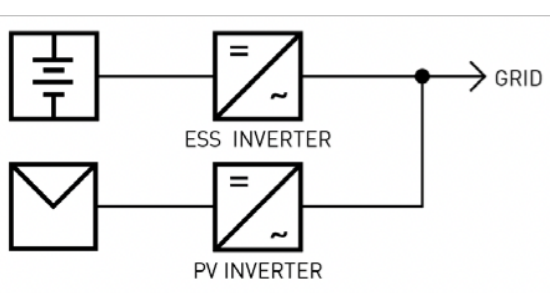

(a) AC coupled

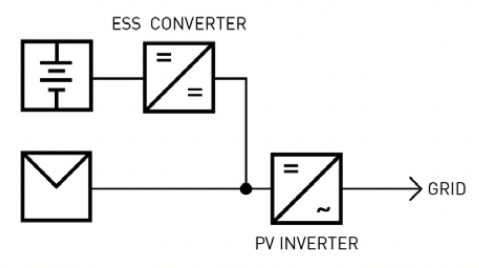

(b) DC coupled

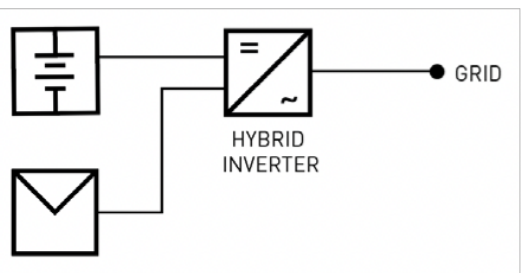

(c) DC-coupled hybrid system

Figure 17. An illustration of various hybrid connections of battery and renewables (Denholm 2017)

\subsection{Reactive Power and Voltage Support}

A battery stores energy with reference to a DC supply, whereas reactive power is a concept related to AC supply. However, a battery can supply reactive power to the grid through an inverter connected to the grid. The current of the inverter can be controlled to be in or out of phase of the voltage of the grid, leading to reactive power support to the grid as needed. A BESS can provide voltage support at the point of common coupling utilizing a slightly different set of 
inverter controls architecture during both charging and discharging operations (as shown in Figure 13). Two common types of inverter control are (1) current-controlled voltage source inverters and (2) voltage-controlled current source inverters. In an idealized case of an AC microgrid, a BESS inverter can be made to control the voltage at the point of common coupling. This can achieved by setting up the BESS inverter as a voltage-controlled current source inverter, while DER inverters are typically current-controlled voltage source inverters (Semënov et al. 2017). The BESS inverter acts instantly to provide only the transient difference between the load current and the total current supplied by the equivalent DER inverters. 


\section{Conclusion and Expected Outcomes}

This document outlines a literature review of distributed generation integration to establish a roadmap for research and demonstration activities for distributed wind integration research. The research activities will be conducted by national laboratory partners under the DOE Wind Energy Technologies Office-funded MIRACL project. Based on a simple literature review, not a comprehensive review, this report summarizes some of the prominent R\&D activities performed for controlling DERs, such as solar PV, wind, and storage, for providing essential reliability services. Then, the relevant findings have been used as inspiration to inform an R\&D roadmap for distributed wind control research.

The MIRACL project envisions distributed wind to provide value to the grid in four different use cases: isolated grid, microgrid, front-of-the-meter, and behind-the-meter distribution system connected projects. For distributed wind turbine systems to more commonly provide essential reliability services in all these use cases, development and demonstration of advanced control methods and communication interfaces within the four proposed MIRACL use cases will be essential. This report ends with a comprehensive research plan that will be developed, simulated, and field-validated in this project using NREL's Flatirons Campus and Sandia's SWiFT-DETL site.

As wind-focused control capabilities are researched under MIRACL, the ability for and benefits from coupling with other synergistic distributed technologies, such as solar PV and energy storage, will be investigated for all use cases. More specifically, wind-storage and wind-solar PV hybrid research will also be investigated, thereby demonstrating many of the aforementioned capabilities for both AC- and DC-coupled systems, demonstrating the capabilities of the mechanical and electrical benefits that a distributed wind turbine system can provide, and evaluating the cost-benefits under different configurations.

A summary of outcomes of this work includes:

1. A demonstrated capability and technical value of MIRACL of distributed wind turbine generators providing a wide range of grid services based on active and reactive power control. Essential reliability services such as fault ride through, inertia, primary and secondary frequency response, and black start for resilience will be investigated. This assessment will be conducted for the most common forms of distributed wind technologies: stall-regulated to active pitch control, and Type 3 and Type 4 turbines.

2. The controls and demonstration for grid-support capabilities will be applied across the different applications of distributed wind use cases, from grid-connected, microgrids, and isolated, including transitions between these states as appropriate.

3. An initial assessment of the ability to implement integrated wind turbine battery storage, most specifically with DC coupling to take advantage of existing advanced power converter technology that is already integrated into the wind turbine generator.

4. Implementation of expanded testing infrastructure at the NREL Flatirons Campus (previously known as National Wind Technology Center) and Sandia's SWiFT/Texas Tech 
University field and PHIL test sites, allowing for expanded testing of potential grid-support services from distributed wind. Scenarios of assessment will also include distribution systems with high renewable energy contributions as well as weak rural grids.

Finally, as DERs are beginning to proliferate, various national and international standards governing the DER interconnections are requiring stringent grid-support functions (such as California's Rule 21) to ensure reliability and resilience of the base grid the DERs serve. Therefore, the findings from the MIRACL project research will help distributed wind technologies meet or exceed such grid codes, as we will be working with the close participation of manufacturers; supply chain, isolated, microgrid, and bulk system operators; and other crossindustry partners. 


\section{References}

Adibi, M., P. Clelland, L. Fink, H. Happ, R. Kafka, J. Raine, D. Scheurer, and F. Trefny. 1987. "Power System Restoration - A Task Force Report." IEEE Transactions on Power Systems 2(2): 271-277. https://doi.org/10.1109/TPWRS.1987.4335118.

Bahramirad, S., F. Katiraei, A. Khodaei, S. R. Kothandaraman, M. Lelic, Z. Li, A. Malekpour, A. Paaso, and A. Zamani. 2018. Research, Development, and Testing of a Master Controller with Applications to the Bronzeville Community Microgrid System. Oakbrook Terrace, IL: Commonwealth Edison Company. DE-OE0000724. https://doi.org/10.2172/1476642.

Baring-Gould, I., K. Burman, M. Singh, S. Esterly, R. Mutiso, and C. McGregor. 2016. Quality Assurance Framework for Mini-Grids. Golden, CO: National Renewable Energy Laboratory. NREL/TP-5000-67374. https://www.nrel.gov/docs/fy17osti/67374.pdf.

Bidram, A., and A. Davoudi. 2012. "Hierarchical Structure of Microgrids Control System." IEEE Transactions on Smart Grid 3(4): 1963-1976. https://doi.org/10.1109/TSG.2012.2197425.

Blaabjerg, F., R. Teodorescu, M. Liserre, and A. V. Timbus. 2006. "Overview of Control and Grid Synchronization for Distributed Power Generation Systems.” IEEE Transactions on Industrial Electronics 53(5): 1398-1409. https://doi.org/10.1109/TIE.2006.881997.

Bowen, T., I. Chernyakhovskiy, and P. Denholm. 2019. Grid-Scale Battery Storage: Frequently Asked Questions. Golden, CO: National Renewable Energy Laboratory. NREL/TP-6A20-74426. https://www.nrel.gov/docs/fy19osti/74426.pdf.

Braun, M., J. Brombach, C. Hachmann, D. Lafferte, A. Klingmann, W. Heckmann, F. Welck, D. Lohmeier, and H. Becker. 2018. "The Future of Power System Restoration: Using Distributed Energy Resources as a Force to Get Back Online.” IEEE Power and Energy Magazine 16(6): 30-41. https://doi.org/10.1109/MPE.2018.2864227.

California ISO. 2020a. Avangrid Renewables Tule Wind Farm: Demonstration of Capability to Provide Essential Grid Services. Folsom, CA: California Independent System Operator. http://www.caiso.com/Documents/WindPowerPlantTestResults.pdf.

California ISO. 2020b. "ISO tests prove wind can play major role in renewable integration." News Release, March 11, 2020. https://www.caiso.com/Documents/ ISOTestsProveWindCanPlayMajorRoleinRenewableIntegration.pdf.

Colthorpe, A. 2017. "California battery's black start capability hailed as 'major accomplishment in the energy industry."” Energy Storage News, May 17, 2017. https://www.energystorage.news/news/california-batterys-black-start-capability-hailed-as-major-accomplishment-i.

Darbali-Zamora, R. 2019. "Photovoltaic inverter voltage regulation performance evaluation using a power hardware-in-the-loop setup on distribution system feeders." PhD diss., University of Puerto Rico. 
Das, T., V. Krishnan, and J. McCalley. 2015. "Assessing the benefits and economics of bulk energy storage technologies in the power grid." Applied Energy 139: 104-118.

https://doi.org/10.1016/j.apenergy.2014.11.017.

Denholm, P. 2017. Evaluating the Technical and Economic Performance of PV Plus Storage Power Plants. Golden, CO: National Renewable Energy Laboratory. NREL/TP-6A20-68737. https://www.nrel.gov/docs/fy17osti/68737.pdf.

Draxl, C., A. Clifton, B.-M. Hodge, and J. McCaa. 2015. "The wind integration national dataset (WIND) toolkit." Applied Energy 151: 355-366. https://doi.org/10.1016/j.apenergy.2015.03.121.

Ela, E., V. Gevorgian, P. Fleming, Y. Zhang, M. Singh, E. Muljadi, A. Scholbrook, et al. 2014. Active Power Controls from Wind Power: Bridging the Gaps. Golden, CO: National Renewable Energy Laboratory. NREL/TP-5D00-60574. doi:10.2172/1117060.

Elkhatib, M., J. Neely, and J. Johnson. 2017. "Evaluation of fast-frequency support functions in high penetration isolated power systems." IEEE $44^{\text {th }}$ Photovoltaic Specialist Conference (PVSC), 25-30 June 2017, Washington, D.C. https://doi.org/10.1109/PVSC.2017.8366506.

Energy Sector Management Assistance Program (ESMAP). 2019. Grid Integration Requirements for Variable Renewable Energy. Washington, D.C.: World Bank.

European Wind Energy Association (EWEA). 2009. "Active Power Control.” Wind Energy: The Facts. Retrieved March 18, 2020. https://www.wind-energy-the-facts.org/active-powercontrol.html.

Fang, X., B.-M. Hodge, V. Krishnan, and F. Li. 2018. "Potential of Wind Power to Provide Flexible Ramping Products and Operating Reserve." IEEE PES General Meeting 2018, 5-10 August 2018, Portland, OR. https://doi.org/10.1109/PESGM.2018.8586436.

GE Energy. 2010. Western Wind and Solar Integration Study. Golden, CO: National Renewable Energy Laboratory. NREL/SR-550-47434. https://doi.org/10.2172/981991.

Gevorgian, V., P. J. Koralewicz, H. N. Pico, S. D. Shah, R. B. Wallen, D. A. Corbus, J. A. Keller, et al. 2019. WGRID-49 GMLC Project Report: Understanding the Role of Short-Term Energy Storage and Large Motor Loads for Active Power Controls by Wind Power. Golden, CO: National Renewable Energy Laboratory. NREL/TP-5D00-72888. https://doi.org/10.2172/1558905.

Gevorgian, V., S. Shah, and P. Koralewicz. 2019. "Modeling Challenges: Dynamic Interactions Between Inverters, Grid Forming Inverters." Challenges for Distribution Planning, Operational and Real-time Planning Analytics Workshop, 17 May 2019, Washington, D.C. https://www.energy.gov/sites/prod/files/2019/08/f65/3.2.b.\%20\%20SETO $\% 20$ Modeling $\% 20$ Workshop $\% 20-\% 20$ NREL.pdf.

Giraldez, J., A. Hoke, P. Gotseff, N. Wunder, M. Emmanuel, A. Latif, E. Ifuku, et al. 2018. Advanced Inverter Voltage Controls: Simulation and Field Pilot Findings. Golden, CO: National Renewable Energy Laboratory. NREL/TP-5D00-72298. https://doi.org/10.2172/1481102. 
Giraldez, J., A. Nagarajan, P. Gotseff, V. Krishnan, A. Hoke, R. Ueda, J. Shindo, M. Asano, and E. Ifuku. 2017. Simulation of Hawaiian Electric Companies Feeder Operations with Advanced Inverters and Analysis of Annual Photovoltaic Energy Curtailment. Golden, CO: National Renewable Energy Laboratory. NREL/TP-5D00-68681. https://doi.org/10.2172/1373489.

Gonzalez, S., J. Johnson, and J. Neely. 2015. "Electrical power system support-function capabilities of residential and small commercial inverters." IEEE $42^{\text {nd }}$ Photovoltaic Specialist Conference (PVSC), 14-19 June 2015, New Orleans, LA.

https://doi.org/10.1109/PVSC.2015.7356281.

Gravagne, R. I., J. Berg, J. White, W.-B. Felipe, A. Summers, D. Schoenwald, and M. Harral. 2018. Use and Testing of a Wind Turbine for the Supply of Balancing Reserves and Wide-Area Grid Stability. Albuquerque, NM: Sandia National Laboratories. SAND2018-773084. https://energy.sandia.gov/wp-content/uploads/2018/10/SWIFT-Report-FINAL.pdf.

Guttromson, R., I. Gravagne, J. White, J. C. Berg, F. Wilches-Bernal, J. Paquette, and C. Hansen. 2017. Use of Wind Turbine Kinetic Energy to Supply Transmission Level Services. Albuquerque, NM: Sandia National Laboratories. SAND2018-3200. https://www.osti.gov/servlets/purl/1489867.

Hansen, A. D. 2012. "Generators and Power Electronics for Wind Turbines." In Wind Power in Power Systems, edited by T. Ackermann. Hoboken: Wiley.

Hobbs, B., V. Krishnan, E. Spyrou, J. Zhang, and R. Zhang. 2018. Coordinated Ramping Product and Regulation Reserve Procurements in CAISO and MISO Using Multi-Scale Probabilistic Solar Power Forecasts. https:/www.energy.gov/sites/prod/files/2018/10/.

Hoke, A. F., M. Elkhatib, A. Nelson, J. Johnson, J. Tan, R. Mahmud, V. Gevorgian, et al. 2017. The frequency-watt function: simulation and testing for the Hawaiian electric companies. Golden, CO: National Renewable Energy Laboratory. NREL/TP-5D00-68884. https://www.nrel.gov/docs/fy17osti/68884.pdf.

Horowitz, K., Z. Peterson, M. Coddington, F. Ding, B. Sigrin, D. Saleem, and S. E. Baldwin. 2019. An Overview of Distributed Energy Resource (DER) Interconnection: Current Practices and Emerging Solutions. Golden, CO: National Renewable Energy Laboratory. NREL/TP-6A2072102. https://www.nrel.gov/docs/fy19osti/72102.pdf.

Howland, M., V. Krishnan, N. Brown, and J. McCalley. 2014. "Assessing the impact of power rate limitation based wind control strategy." IEEE PES Transmission \& Distribution Conference \& Exposition, 14-17 April 2014, Chicago, IL. https://doi.org/10.1109/TDC.2014.6863504.

Huang, B., V. Krishnan, and B.-M. Hodge. 2018. "Analyzing the Impacts of Variable Renewable Resources on California Net-Load Ramp Events." IEEE PES General Meeting 2018, 5-10 August 2018, Portland, OR. https://doi.org/10.1109/PESGM.2018.8585852.

IEEE. 2017. 2030.7-2017 - IEEE Standard for the Specification of Microgrid Controllers. Piscataway, NJ: IEEE Standards Association. 
IEEE. 2018. 1547-2018 - Standard for Interconnection and Interoperability of Distributed Energy Resources with Associated Electric Power Systems Interfaces. Piscataway, NJ: IEEE Standards Association.

Jain, H., G.-S. Seo, E. Lockhart, V. Gevorgian, and B. Kroposki. 2020. "Blackstart of Power Grids with Inverter-Based Resources." IEEE Power and Energy Society General Meeting (IEEE PES GM), 2-6 August 2020, Montreal, Canada.

Jiang, Z., and X. Yu. 2008. "Modeling and control of an integrated wind power generation and energy storage system." IEEE Power \& Energy Society General Meeting, 26-30 July 2008, Calgary, Canada. https://doi.org/10.1109/PES.2009.5275753.

Jiang-Hafner, Y., H. Duchen, M. Karlsson, L. Ronstrom, and B. Abrahamsson. 2008. "HVDC with voltage source converters - a powerful standby black start facility." 2008 IEEE/PES Transmission and Distribution Conference and Exposition, 21-24 April 2008, Chicago, IL. https://doi.org/10.1109/TDC.2008.4517039.

Johnson, B. B., M. Sinha, N. G. Ainsworth, F. Dörfler, and S. V. Dhople. 2016. "Synthesizing Virtual Oscillators to Control Islanded Inverters." IEEE Transactions on Power Electronics 31(8): 6002-6015. https://doi.org/10.1109/TPEL.2015.2497217.

Johnson, J., S. Gonzalez, and D. B. Arnold. 2017. "Experimental distribution circuit voltage regulation using der power factor, volt-var, and extremum seeking control methods." IEEE $44^{\text {th }}$ Photovoltaic Specialist Conference (PVSC), 25-30 June 2017, Washington, D.C.

Kahrobaee, S., M. C. Algrain, and S. Asgarpoor. 2013. "Investigation and Mitigation of Transformer Inrush Current during Black Start of an Independent Power Producer Plant." Energy and Power Engineering 5(1): 1-7.

Krishnan, V., T. Das, and J. McCalley. 2014. "Impact of short-term storage on frequency response under increasing wind penetration." Journal of Power Sources 257: 111-119.

Kroposki, B., B. Johnson, Y. Zhang, V. Gevorgian, P. Denholm, B.-M. Hodge, and B. Hannegan. 2017. "Achieving a 100\% renewable grid: Operating electric power systems with extremely high levels of variable renewable energy." IEEE Power and Energy Magazine 15(2): 61-73.

Lio, W. H., M. Mirzaei, and G. C. Larsen. 2018. "On wind turbine down-regulation control strategies and rotor speed set-point.” Journal of Physics: Conference Series. 1037(3): 032040.

Lori, B., C. Jaquelin, and W. Xi. March 2014. Wind and Solar Energy Curtailment: Experience and Practices in the United States. Golden, CO: National Renewable Energy Laboratory. NREL/TP-6A20-60983. https://doi.org/10.2172/1126842.

Lu, M., G. Seo, M. Sinha, F. Rodriguez, S. Dhople, and B. Johnson. 2019. "Adaptation of Commercial Current-controlled Inverters for Operation with Virtual Oscillator Control." IEEE Applied Power Electronics Conference and Exposition (APEC), 17-21 March 2019, Anaheim, CA. https://doi.org/10.1109/APEC.2019.8722234. 
Madjidian, D. 2016. "Scalable minimum fatigue control of dispatchable wind farms." Wind Energy 19(10): 1933-1944.

Miller, N. W. 2013. "GE Wind Plant Advanced Controls." $1^{\text {st }}$ International Workshop on Grid Simulator Testing of Wind Turbine Drivetrains, 13 June 2013. https://www.nrel.gov/ grid/assets/pdfs/turbine_sim_12_advanced_wind_plant_controls.pdf.

Miller, N. W. 2014. "GE Experience with Turbine Integrated Battery Energy Storage." IEEE Power and Society.

Milligan, M. 2018. "Sources of grid reliability services.” The Electricity Journal 31(9): 1-7.

Muljadi, E., N. Samaan, V. Gevorgian, J. Li, and S. Pasupulati. 2010. "Different Factors Affecting Short Circuit Behavior of a Wind Power Plant." 2010 IEEE Industry Applications Society Annual Meeting, 3-7 October 2010, Houston, TX. https://doi.org/10.1109/IAS.2010.5616819.

Muljadi, E., V. Gevorgian, M. Singh, and S. Santoso. 2012. "Understanding inertial and frequency response of wind power plants." IEEE Symposium on Power Electronics and Machines in Wind Applications, 16-18 July 2012, Denver, CO. https://doi.org/10.1109/PEMWA.2012.6316361.

National Grid ESO. 2019. Black Start from Non-Traditional Generation Technologies: Technology capability and readiness for distributed restoration. Warwick, UK: National Grid Electricity System Operator. https://www.nationalgrideso.com/document/148201/download.

Nock, D., V. Krishnan, and J. McCalley. 2014. "Dispatching Intermittent Wind Resources for Ancillary services via Wind Control and its Impact on Power System Economics." Renewable Energy 71: 396-400. https://doi.org/10.1016/j.renene.2014.05.058.

North American Electric Reliability Corporation (NERC). 2019. Reliability Guideline: Primary Frequency Control. Atlanta, GA: NERC.

NREL. 2017. National Renewable Energy Laboratory Dual-Staged Microgrid Controller Procurement Details. Golden, CO: National Renewable Energy Laboratory. https://www.nrel.gov/esif/assets/pdfs/microgrid-controller-dual-stage-procurement-details-52017.pdf.

NREL. 2020a. "Eastern Renewable Generation Integration Study." https://www.nrel.gov/grid/ergis.html.

NREL. 2020b. "Western Wind and Solar Integration Study." http://www.nrel.gov/grid/wwsis.html.

Olivares, D. E., A. Mehrizi-Sani, A. H. Etemadi, C. A. Cañizares, R. Iravani, M. Kazerani, A. H. Hajimiragha, et al. 2014. "Trends in Microgrid Control." IEEE Transactions On Smart Grid 5(4): 1905-1919. https://doi.org/10.1109/TSG.2013.2295514. 
Palmintier, B. 2019. "Advanced Inverters: (1547) Capabilities, Experiences, and Interaction with Hosting Capacity." NRCan Canada-USA-Mexico Workshop on Hosting Capacity with Advanced Inverter Functions, 19 February 2019, Montreal, Canada.

Peng, Q., Q. Jiang, Y. Yang, T. Liu, H. Wang, and F. Blaabjerg. 2019. "On the Stability of Power Electronics-Dominated Systems: Challenges and Potential Solutions." IEEE Transactions on Industry Applications 56(6): 7657-7670.

Pokharel, B., O. Ojo, and A. Balogun. 2015. "Standalone Operation of a DFIG-based Wind Turbine System with Integrated Energy Storage." IEEE 6th International Symposium on Power Electronics for Distributed Generation Systems (PEDG), 22-25 June 2015, Aachen, Germany. https://doi.org/10.1109/PEDG.2015.7223060.

Ryan, W., and B. Mark. 2019. 2018 Wind Technologies Market Report. Berkeley, CA: Lawrence Berkeley National Laboratory. DOE/GO-102019-5191. https://doi.org/10.2172/1559241.

Semënov, D., G. Mirzaeva, C. Townsend, and G. Goodwin. 2017. "A battery storage control scheme for AC microgrids." 20th International Conference on Electrical Machines and Systems (ICEMS), 11-14 August 2017, Sydney, Australia. https://doi.org/10.1109/ICEMS.2017.8056512.

Singh, M., A. Allen, E. Muljadi, and V. Gevorgian. 2014. "Oscillation Damping: A Comparison of Wind and Photovoltaic Power Plant Capabilities." IEEE Symposium on Power Electronics and Machines for Wind and Water Applications, 24-26 July 2014, Milwaukee, WI. https://doi.org/10.1109/PEMWA.2014.6912216.

Singh, M., A. J. Allen, E. Muljadi, V. Gevorgian, Y. Zhang, and S. Santoso. 2015. "Interarea Oscillation Damping Controls for Wind Power Plants." IEEE Transactions on Sustainable Energy 6(3): 967-975. https://doi.org/10.1109/TSTE.2014.2348491.

Singh, M., E. Muljadi, and V. Gevorgian. 2012. "Test Cases for Wind Power Plant Dynamic Models on Real-Time Digital Simulator." IEEE Symposium on Power Electronics and Machines in Wind Applications, 16-18 July 2012, Denver, CO. https://www.nrel.gov/docs/fy12osti/55314.pdf.

Singh, M., E. Muljadi, J. Jonkman, V. Gevorgian, I. Girsang, and J. Dhupia. 2014. Simulation for Wind Turbine Generators-With FAST and MATLAB-Simulink Modules. Golden, Colorado: National Renewable Energy Laboratory. NREL/TP-5D00-59195. https://doi.org/10.2172/1130628.

Tamrakar, U., D. Shrestha, M. Maharjan, B. P. Bhattarai, T. M. Hansen, and R. Tonkoski. 2017. "Virtual inertia: Current trends and future directions." Applied Sciences 7(7): 654.

Ton, D., and Reilly, J. 2017. "Microgrid Controller Initiatives: An Overview of R\&D by the U.S. Department of Energy." IEEE Power \& Energy Magazine 15(4): 24-31.

doi:10.1109/MPE.2017.2691238.

Ton, D., and Smith, M. A. 2012. "The U.S. Department of Energy's Microgrid Initiative.” The Electricity Journal 25(8): 84-94. https://doi.org/10.1016/j.tej.2012.09.013. 
Vyver, J. V. 2016. "Support of grid frequency control by wind turbines.” PhD diss., Ghent University.

Wilches-Bernal, F., C. Lackner, J. H. Chow, and J. J. Sanchez-Gasca. 2019. "Effects of Wind Turbine Generators on Inter-Area Oscillations and Damping Control Design." Proceedings of the 52nd Hawaii International Conference on System Sciences, 8-11 January 2019, Grand Wailea, HI.

Wilches-Bernal, F., J. H. Chow, and J. J. Sanchez-Gasca. 2015. "A fundamental study of applying wind turbines for power system frequency control." IEEE Transactions on Power Systems 31(2): 1496-1505.

Yuan, X., F. Wang, D. Boroyevich, Y. Li, and R. Burgos. 2009. "DC-link Voltage Control of a Full Power Converter for Wind Generator Operating in Weak-Grid Systems." IEEE Transactions on Power Electronics 24(9): 2178-2192.

Zeng, J., J. Ning, X. Du, T. Kim, Z. Yang, and V. Winstead. 2019. “A Four-Port DC-DC Converter for a Standalone Wind and Solar Energy System." IEEE Transactions on Industry Applications 56(1): 446-454.

Zhang, B., W. Hu, P. Hou, J. Tan, M. Soltani, and Z. Chen. 2017. "Review of Reactive Power Dispatch Strategies for Loss Minimization in a DFIG-based Wind Farm." Energies 10: 856. doi:10.3390/en1007085. 